\title{
QUALITY PAPER Exploring research on quality and reliability management through text mining methodology
}

\author{
Daniel Carnerud \\ Department of Quality Technology and Management, Mid Sweden University, \\ Östersund, Sweden
}

Quality and reliability

management

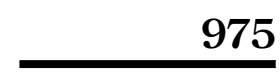

Received 6 March 2015 Revised 24 August 2015 11 March 2016 Accepted 23 March 2016

\begin{abstract}
Purpose - The purpose of this paper is to explore and describe research presented in the International Journal of Quality \& Reliability Management (IJQRM), thereby creating an increased understanding of how the areas of research have evolved through the years. An additional purpose is to show how text mining methodology can be used as a tool for exploration and description of research publications.

Design/methodology/approach - The study applies text mining methodologies to explore and describe the digital library of IJQRM from 1984 up to 2014. To structure and condense the data, k-means clustering and probabilistic topic modeling with latent Dirichlet allocation is applied. The data set consists of research paper abstracts.

Findings - The results support the suggestion of the occurrence of trends, fads and fashion in research publications. Research on quality function deployment (QFD) and reliability management are noted to be on the downturn whereas research on Six Sigma with a focus on lean, innovation, performance and improvement on the rise. Furthermore, the study confirms IJQRM as a scientific journal with quality and reliability management as primary areas of coverage, accompanied by specific topics such as total quality management, service quality, process management, ISO, QFD and Six Sigma. The study also gives an insight into how text mining can be used as a way to efficiently explore and describe large quantities of research paper abstracts. Research limitations/implications - The study focuses on abstracts of research papers, thus topics and categories that could be identified via other journal publications, such as book reviews; general reviews; secondary articles; editorials; guest editorials; awards for excellence (notifications); introductions or summaries from conferences; notes from the publisher; and articles without an abstract, are excluded.

Originality/value - There do not seem to be any prior text mining studies that apply cluster modeling and probabilistic topic modeling to research article abstracts in the IJQRM. This study therefore offers a unique perspective on the journal's content.
\end{abstract}

Keywords TQM, Quality management, Cluster modelling, Management fashion,

Probabilistic topic modelling, Reliability management

Paper type Research paper

\section{Introduction}

Concerns about trends, fashions and fads in management research and practice is not a new phenomenon in the academic community (Abrahamson, 1996, 2009; Abrahamson and Eisenman, 2008; Abrahamson and Fairchild, 1999; Czarniawska, 2007, 2011a, 2014; Czarniawska and Panozzo, 2008; Parush, 2008; Starbuck, 2009; Trout, 2004). Researchers within the field of quality management $(\mathrm{QM})$ and total quality management (TQM) are no exception to this general rule: the issue has fueled debate for many years with even Deming (1986) taking a stand urging scientists and practitioners to promote valid quality improvement measures instead of just flaunting slogans (Dahlgaard-Park, 1999, 2011; Dahlgaard-Park et al., 2013; Rocco and Parry, 2011; Sila and Ebrahimpour, 2002; Sousa and Voss, 2002; Van Der Wiele et al., 2000). As the ongoing digitalization of society offers access to an ever increasing amount of data as well as ever more powerful hardware and software, new methods of exploring and describing trends in digital material continuously arise (Glenisson et al., 2005; Delen and Crossland, 2008; Dereli et al., 2011; Rosen-Zvi et al., 2010).

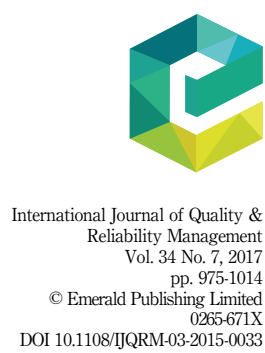


IJQRM

34,7

976

Against this backdrop, the International Journal of Quality \& Reliability Management $(I J Q R M)$ offers an interesting object of study as it is one of few research publications dealing with QM and other aspects of business and manufacturing improvements that has a digital publication archive dating as far back as 1984. This unbroken sequence of publications with more than 240 issues available makes IJQRM interesting for research into how a publication and its research articles have evolved historically (Aggarwal and Zhai, 2012; Garfield et al., 2003; Kent, 2014; Larose, 2005; Liu, 2011; Miner, 2012; Weiss et al., 2012). A retrospective view on trends, fashions and fads are not useful for historical purposes alone, but can also help editors and publishers of today to gain a better understanding of the dynamics of the product, and make strategic decisions accordingly (Moro et al., 2015; Finch, 1999; Heim and Field, 2007; Köksal et al., 2011). Tapping into the historical progression of a research journal can also offer a helping hand to researchers in the midst of the publishing process by identifying the optimal journal for publication by providing information about what kind of research historically has been a cornerstone or stronghold of a certain publication (Becher and Trowler, 2001; Czarniawska, 2011 b, 2014; Glenisson et al., 2005; Rosen-Zvi et al., 2010). Finally, analyses on research journals could serve as a way to identify upcoming trends, which might help in the decision making for future research as well as with the alignment or direction of research programs (Delen and Crossland, 2008; Dereli et al., 2011). Hence, this study aims to, with the help of text mining methodology, explore and describe the digital library of $I J Q R M$ of the last 30 years, looking for possible trends, fashions and fads. The study does not aim to reveal or determine reasons for, or the dynamics behind, the emergence of, trends, fashions and fads in research, even if the topic is important and closely related to the issue of whether such trends really exist. The study does, however, address the possibilities and limitations of the tools and techniques used in this research.

\section{Theoretical frame of reference}

Academic contributions are valued differently within different academic disciplines. In general, the academic paper is seen as the highest ranking form of publication (Becher and Trowler, 2001). This means that by studying academic papers one can obtain an insight on which issues and topics have been addressed in IJQRM throughout the years - in other words which fashions and trends have prevailed. Czarniawska (2011a) challenges the perhaps common notion of fashion in research being something negative. According to Czarniawska (2011a), fashion is both a cultural phenomenon and a production system, and further suggests it is necessary to have a balanced approach between the two. Fashion, understood as the prevalent way of doing something, has a close connection to what Kuhn and others call paradigm (Czarniawska, 2011a). The problem seems to be that instead of studying fashion, or paradigms, so as to better understand them, researchers get stuck on moralizing about the issue (Czarniawska, 2011a). From this perspective it is easy to miss the potentially progressive momentum of fashion. In a way the very concept, or meaning of the word, "fashion" is paradoxical, both promoting innovation and reflecting "dime a dozen mass-production" (Czarniawska, 2011a). As summarized by Czarniawska (2011a): "On the one hand, its variety is limited by the iron cage of existing institutions, which fashion reproduces; on the other hand, fashion is engaged in a constant subversion of the existing institutional order, gnawing at its bars." (Czarniawska, 2011a, p. 601)

Czarniawska and Panozzo (2008) shed further light on the issue with their modern interpretation of Gabriel Tarde who stated that fashion was to be contrasted with custom. Inventions and innovations, he argues, are improved imitations of a custom and claim superiority: first, on the base of value-added qualities; and second, on the basis of who coined and circulated them (Czarniawska and Panozzo, 2008). However, to determine which driving force is actually pushing a certain fashion becomes complicated as the two easily interlace 
(Czarniawska and Panozzo, 2008). Sometimes the latter factor, the identity of the spokesperson, can blind us to the former factor, the real quality of a new fashion (Czarniawska and Panozzo, 2008). The third distinguishing feature of superiority for a new fashion is that it has many allies in other areas, being well anchored in existing research and so is not threatening to existing institutionalized structures (Czarniawska and Panozzo, 2008).

Another explanation for the occurrence of trends and fads in research could be scholars' attraction toward novelty, and consequently their limited interest and tolerance for the imitation and use of old theories and methods (Starbuck, 2009). Then again, it is also possible that we would observe less volatility in the academic community if earlier theories were actually giving valuable explanations; researchers would then possibly have more motivation to incorporate them instead of wasting time and energy constructing new ones (Starbuck, 2009).

Finally, Trout (2004) acknowledges the rise and fall of what he refers to as intellectual fashion. One of his main points is the divergence between epistemology and classical sciences. The latter, like theoretical physics, offer humans useful guidance about important matters; indeed classical sciences do not aim to be normative, as opposed to epistemology (Trout, 2004). He further states that if epistemology is to live up to its normative promise it must embrace what he calls ameliorative psychology, and start its journey toward epistemological excellence. Epistemological excellence can be defined as the efficient allocation of cognitive resources to robustly reliable reasoning strategies, applied to significant problems (Trout, 2004). A way of pursuing this road is to focus on hard theories, those that are easier to subject to reliable testing, as opposed to soft theories (Trout, 2004). Scientific computation of research publications offers a contrast to traditional literature reviews as a base for discussing trends, fashions and fads in research; and with epistemological excellence in mind could perhaps prove to be a way of looking into the question of trends, fashions and fads in research while at the same time honoring the call for reliable testing.

\section{Text mining}

A majority of business data are stored in unstructured form (i.e. text), some researchers citing numbers as high as 85-90 percent (Larose, 2005). With this background, a research paradigm labeled knowledge discovery in databases emerged, later evolving into data mining and in a similar manner into knowledge discovery in textual database. This in turn evolved into text data mining and the field finally settled on simply text mining (Larose, 2005). According to Miner (2012), text mining is one example of the larger academic practice that he labels text analytics which brings together and cuts across the disciplines of statistics, machine learning, management science, artificial intelligence, computer science and other disciplines.

Over the last few decades, data mining has been used frequently within business intelligence (BI), and text mining is expanding as a method to extract knowledge (Moro et al., 2015; Chakrabarti, 2003; Kent, 2014). Purposeful text mining rests on the same assumption as data mining, that is, looking for valuable patterns, correlations and trends in large data sets with the help of statistical and mathematical techniques; a process too complex and resource demanding for manual processing (Aggarwal and Zhai, 2012; Liu, 2011; Weiss et al., 2012). Hence, text mining is increasingly used in quality and business development with studies ranging from credit and insurance assessments and customer feedback loops to reviews of project, process and failure reports (Moro et al., 2015; Choudhary et al., 2009; Finch, 1999; Heim and Field, 2007; Kent, 2014; Khamis et al., 2013; Köksal et al., 2011; Lo, 2008).

Research on QM and TQM-related publications has been undertaken previously (Dahlgaard-Park et al., 2013; Dereli et al., 2011; Sila and Ebrahimpour, 2002). However, none of these studies have applied text mining methodology on research paper abstracts to identify trends and patterns and none have covered a time span of 30 years. The reasons for
Quality and reliability management 
IJQRM

34,7

978 using abstracts in the study instead of complete articles are mainly practical, as abstracts are easily collected and faster to process (Delen and Crossland, 2008). As abstracts are often seen as a distillation of the main findings in an academic article the unique points in the study should be reflected there, hence the approach of collecting and studying journal abstracts is common in text mining (Delen and Crossland, 2008). This is also facilitated by the fact that, as opposed to complete academic articles, journal abstracts are generally accessible for all visitors, and free of charge, making them cost-effective for large scale automatized collection. The IJQRM website operates according to these norms and it was therefore possible to collect abstracts from IJQRM's digital archive in this manner.

\section{Data source}

\section{The IJQRM}

The IJQRM started in 1984 and has been in print annually since. In 1998, the International Journal of Quality Science merged into IJQRM. The subject area of IJQRM is Management Science and Operations and it is one of the few research publications in the area with an unbroken publication track record of more than 30 years, making it suitable for longitudinal studies and the identification of widespread trends and fashions in the research community. The journal describes itself and its topic coverage as follows:

The International Journal of Quality \& Reliability Management (IJQRM) deals with all aspects of business and manufacturing improvements, from the training of senior managers, to innovations in processing and production to raise standards of product quality. It is this unique blend of managerial and technical material that makes IJQRM a valuable resource for senior managers striving for higher standards. Coverage includes:

- Equipment maintenance \& availability.

- Gauging, calibration \& measurement.

- Life cycle costing \& sustainability.

- Reliability Management of Systems.

- Green Marketing.

- Product liability.

- Product testing techniques \& systems.

- Quality function deployment (QFD).

- Reliability \& quality education \& training.

- Productivity improvements \& regulatory standards for quality.

- Statistical process control.

- System modelling.

- Teamwork information your company needs to achieve and maintain competitive standards.

More information about the journal can be found at the journals website, http:// emeraldgrouppublishing.com/products/journals/journals.htm?id=ijqrm, where the data have been downloaded.

\section{Methodology}

Data mining process

Within the field of text and data mining there has developed a Cross Industry Standard Process for Data Mining (CRISP-DM) which consists of six phases: business understanding, 
data understanding, data preparation, modeling, evaluation and deployment (Kurgan and Musilek, 2006). The phases are interconnected through feedback loops. This both implies that text and data mining is an iterative and dynamic process rather than a sequential process. This means that going backwards and re-doing stages on account of new results and insights further along the pathway is the conventional way of operating (Kurgan and Musilek, 2006). This study has been conducted according the CRISP-DM standard and an overview of the work process is described below:

- Business understanding includes definition of the study objectives, formulation of the problem and formation of the strategy to tackle the problem (Kurgan and Musilek, 2006). This study was driven by an interest to explore and describe QM research with the help of text mining methodology. The aim being to create an increased understanding of how the areas of research have evolved through the years.

- Understanding data refers to the collection and initial exploration and evaluation of the data, allowing for a possible change in scope and strategy (Kurgan and Musilek, 2006). After a comparative examination of QM journals, IJQRM turned out to be a suitable object of study as the journal's digital archive starts in 1984, which is among the earliest in its field, providing a basis for longitudinal studies. Also, the IJQRM database permitted automatized data collection, which was a prerequisite for this study. Data that were available from 1984 was: author(s), title, abstract and year of publication. Examples of other information that became standard later on in the publication's history are keywords, which were established in 1987, and type of publication (research paper, book review, editorial, etc.) which started to be systematically classified in 1992-1994.

- Preparing data includes cleaning the data of distorting information and values as well as narrowing down the elements and variables to be included and processed (Marbán et al., 2009). Given the study objectives it was decided to use research paper abstracts and year of publication as the principal data source. The main issue became to isolate the research paper abstracts from other journal content such as book reviews, general reviews, secondary articles, editorials, guest editorials, awards for excellence (notifications), introductions or summaries from conferences and notes from the publisher. As noted above the systematic use of paper classification was not in place until the mid-1990s, thus the sorting of data before this date needed to be done manually. Manual handling showed that most publications in the 1980s were research papers - other content as exemplified above is a later novelty which may also explains why paper classification was a "non-issue" in the 1980s. Connected to the issue of paper type, it became necessary, through random sampling, to manually verify that the systematic classification of papers in the archive database was accurate, so confirming that research papers really were research papers, editorials were editorials, etc. The paper classification was found to be highly reliable. Finally, it was necessary to confirm that all classified research papers had a corresponding research paper abstract and year of publication.

- The modeling phase concerns the choice and calibration of methods to analyze the data (Marbán et al., 2009). Cluster analysis with the k-means clustering algorithm was chosen as the principal method of data analysis; a detailed description of the section cluster analysis is provided below. In order to obtain an overall view of the dataset as well as a more delimited perspective on specific time periods, modeling was carried out both on the extensive data and on demarcated phases in time. Since the data set covers a time period of 31 years (1984-2014) time intervals of about six years were considered suitable as they gave some room for trends, fashions and fads to surge

Quality and reliability management 
IJQRM

34,7

980

and fall within each interval; moreover, it created five time series which could be compared. To fit 31 years into five time periods, the surplus year was added to the first time period (1984-1990) so that it contained seven years instead of six, on the basis that the number of research paper abstracts in the 1980s is considerably fewer than later on. The five time periods thus became: 1984-1990, 1991-1996, 1997-2002, 2003-2008 and 2009-2014.

- Evaluation of the modeling means that results are validated and compared with the objectives of the study (Marbán et al., 2009). In addition to visual aids such as histograms, Pareto diagrams and pie-charts, this study used probabilistic topic modeling. The latent Dirichlet allocation (LDA) model, a distributed algorithm, was used to analyze and evaluate the results. It is described in more detail in the section "probabilistic topic modeling."

- Deployment relates to the objectives of the study and ensures that the results are applied accordingly (Marbán et al., 2009). The discussion and conclusions in this study are considered to correspond to the deployment phase of CRISP-DM.

\section{Word vector generation}

Regardless what type of text mining venture is attempted, it is necessary to transform the unstructured data (text) into structured data (numbers) through word vector creation (Larose, 2005; Miner, 2012). Hence, word vectors needed to be created for both cluster analysis as well as probabilistic topic modeling. Term frequency - inverse document frequency (tf-idf) is seen as an effective way of generating word vectors with systematic, unique and relevant weighting of words (Weiss et al., 2012). Tf-idf was thus used for word vector creation in the cluster modeling phase. Apart from tf-idf no other weighting or pruning method was used, although so called stop words (and, so, yet, etc.) were removed as they slow down computation and do not add any relevant information for the cluster modeling or analysis. In probabilistic topic modeling every word is assigned a probability for every topic which renders the tf-idf formula incompatible, instead, word-frequency is the primary method for generating word vectors (Blei, 2012; Newman et al., 2006). Word-frequency was therefore used for probabilistic topic modeling. As stop words had been removed prior to cluster modeling they naturally became excluded in the topic modeling phase, and as with cluster modeling no other weighting or pruning method was used.

\section{Cluster analysis}

Cluster analysis is a collection of multivariate techniques whose main goal is to group data based on its inherent characteristics (Hair et al., 2014). The point is to classify an observation and assign affiliation to one specific cluster - i.e. the same observation cannot be assigned to several different clusters (Hair et al., 2014). Cluster analysis should primarily be seen as an exploratory and descriptive technique since results are highly dependent on the specific variables used in the dataset and clusters will always be formed regardless of the existence of any actual structure in the data (Hair et al., 2014). If it is intended to make inferences and generalizations from sample to population, then care must be taken as they are prone to error and need to be thoroughly justified (Hair et al., 2014). According to Hair et al. (2014) cluster analysis is specifically suitable for, and often used in, research concerning taxonomy description, data simplification and relationship identification. Taxonomy description refers to an exploratory and empirically based classification of objects that results in a formation of a taxonomy (Hair et al., 2014). Data simplification refers to group data and narrowing down variables and characteristics so that general patterns unfold rather than a myriad of unique observations (Hair et al., 2014). Relationship identification concerns detection of 
underlying structures and patterns in the overall data set that become apparent after clusters are formed, revealing links and associations that otherwise risk being obscured if individual classifications of data are made (Hair et al., 2014). As the study's purpose falls both within taxonomy description and relationship identification, cluster analysis was chosen as the principal method of analysis.

Cluster analysis can be divided into two categories: hierarchical and nonhierarchical (Hair et al., 2014). Generally hierarchical procedures are preferred when fast computations are favored and the sample size is moderate, below 1,000 (Hair et al., 2014). Nonhierarchical procedures are preferred when the number of clusters is known or can be justified by a practical objective or theoretical basis and when outliers can cause concern, i.e. nonhierarchical methods are less sensitive to outliers (Hair et al., 2014). As the aim was to find observable differences and similarities between time periods, and the overall dataset consisted of 1,475 observations, nonhierarchical measures were thought to be most appropriate, which initial testing and modeling confirmed. Even if several nonhierarchical clustering algorithms exist, k-means clustering algorithms dominate and are often used as a synonym for nonhierarchical clustering algorithms all together (Hair et al., 2014). The issue of choosing the optimal k-means algorithm depends on the data at hand as well as which algorithms are available in the software package used (Arthur and Vassilvitskii, 2007; Jain, 2010; Stuti and Veenu, 2013). RapidMiner Studio (C was used for cluster modeling; and experimentation revealed that using squared Euclidean distance as a divergence measure with Bregman divergences as a measure gave stable results.

Regardless of whether hierarchical or nonhierarchical clustering procedures are used, one of the critical issues at hand is choosing an appropriate stopping rule, i.e. to determine which number of clusters best represent the data structure (Hair et al., 2014; Miner, 2012; Weiss et al., 2012). There does not exist any standard objective selection process for choosing stopping rules; in addition, the specific theoretical and practical research situation needs to be taken into consideration as important conceptual issues may lie embedded in the data, e.g. manageability and communicability (Hair et al., 2014). Thus, a combination of heterogeneity change, a measure of how the observations in each cluster differ from each other, and the avoidance of small, and single-member, clusters were applied in the study as it was judged to be a good way of balancing the practical aspects at hand with the purpose of the study. Modeling then started on the overall data set and testing was stopped at eight clusters as additional clusters resulted in the creation of a new extremely small cluster, less than 2 percent, and no overall changes in results, see Table I. For analytic and comparability purposes, in the following modeling sequences, the amount of clusters was kept to eight. Coincidentally, no other modeling session contained a cluster with less than 2 percent of the modeling data, which could be seen as further justification for the chosen amount of clusters. As can be seen in Table I, clusters 3 and 4 contained a majority of all

\begin{tabular}{|c|c|c|c|c|c|c|c|c|}
\hline & 4 clusters & 5 clusters & 6 clusters & 7 clusters & 8 clusters & $\begin{array}{c}\text { Cluster } 3 \text { into } \\
8 \text { clusters }\end{array}$ & $\begin{array}{c}\text { Cluster } 4 \text { into } \\
8 \text { clusters }\end{array}$ & \\
\hline Cluster 0 & $107(7 \%)$ & $132(9 \%)$ & $641(43 \%)$ & $355(24 \%)$ & $128(8 \%)$ & $47(7 \%)$ & $16(5 \%)$ & \\
\hline Cluster 1 & $703(48 \%)$ & $652(44 \%)$ & $101(7 \%)$ & $47(3 \%)$ & $46(3 \%)$ & $46(7 \%)$ & $54(16 \%)$ & \\
\hline Cluster 2 & $536(36 \%)$ & $130(9 \%)$ & $414(28 \%)$ & $131(8 \%)$ & $104(7 \%)$ & $79(12 \%)$ & $24(7 \%)$ & \\
\hline Cluster 3 & $129(9 \%)$ & $459(31 \%)$ & $89(6 \%)$ & $663(45 \%)$ & $631(43 \%)$ & $143(23 \%)$ & $16(5 \%)$ & \\
\hline Cluster 4 & & $102(7 \%)$ & $129(9 \%)$ & $101(7 \%)$ & $334(23 \%)$ & $82(13 \%)$ & $64(19 \%)$ & \\
\hline Cluster 5 & & & $101(7 \%)$ & $96(7 \%)$ & $98(7 \%)$ & $23(4 \%)$ & $32(9 \%)$ & Table I. \\
\hline Cluster 6 & & & & $82(6 \%)$ & $103(7 \%)$ & $119(19 \%)$ & $19(6 \%)$ & Results from \\
\hline Cluster 7 & & & & & $31(2 \%)$ & $92(15 \%)$ & $109(33 \%)$ & clustering IJQRM \\
\hline Total & 1,475 & 1,475 & 1,475 & 1,475 & 1,475 & 631 & 334 & abstracts 1984-2014 \\
\hline
\end{tabular}

Quality and reliability management

981 
IJQRM

34,7

982

data (66 percent) which is why they were further broken up into eight new clusters. Following this initial sort, modeling on the five time periods was executed, the results are shown in Table II.

In cluster analysis there exists no single method for validating, evaluating and labeling generated clusters (Hair et al., 2014). This troubling fact is even more of a concern when it comes to evaluation of unstructured data (text) clustering as this is still a relatively novel area of research and classical processes for validating structured data (numbers) are not applicable (Aggarwal and Zhai, 2012). As the purpose of the study was exploratory, the aim being to look for underlying, hidden, structures in the data, no prior labels had been assigned. Consequently, there existed no labeling schedule to compare against. In other circumstances labeling beforehand is an approved and effective process of operating (Miner, 2012). However, in this study validation, evaluation and labeling of each cluster needed to be done following cluster modeling. One way to go about this is to use manual and qualitative processing, however, with large amounts of data automated procedures are often preferred (Weiss et al., 2012). As the data set was deemed large and unsuitable for manual classification automated procedures were selected. One automated procedure on the rise for this purpose is probabilistic topic modeling (Mimno, 2012; Meeks and Weingart, 2012). As probabilistic topic modeling has shown great potential in the areas of historiography and bibliometric it was picked for the validation, evaluation and labeling of the created clusters.

\section{Probabilistic topic modeling}

Probabilistic topic modeling encompasses several associated methods that group words into topics on the basis of their most probable association (Blei et al., 2003; Newman et al., 2009). Although it is a relatively new method, topic models are generally considered to be a fast and effective way to identify and portray the most frequently occurring and probable themes and subjects in unstructured data sets (Xie and Xing, 2013). One well tested and conventional distributed algorithm for probabilistic topic modeling is the LDA (Welling et al., 2008). As LDA is well accepted, well documented and available through the $\mathrm{R}$ topic modeling package, it was chosen for topic modeling in this study. $\mathrm{R}$ is a free software environment for statistical computing and graphics available for download at https://cran.r-project.org/

Simplified, topic models generate topic-characterized columns. Each column contains all the words in the data set, and words nearer the top of the column are more likely to be found together in the specific observation cluster, than words further down the same column (Blei et al., 2003). Exemplifying with the help of results presented in Table AI, it means that topics, research paper abstracts, in cluster 0 have a high probability of covering various aspects of TQM, such as performance, implementation and manufacturing. Since each word in a data set has a probability to be associated with

Table II.

Results from clustering $I J Q R M$ abstracts into five time periods from 1984 to 2014

\begin{tabular}{llllcc}
\hline & $1984-1990$ & $1991-1996$ & $1997-2002$ & $2003-2008$ & $2009-2014$ \\
\hline Cluster 0 & $15(9 \%)$ & $31(10 \%)$ & $40(12 \%)$ & $21(6 \%)$ & $18(5 \%)$ \\
Cluster 1 & $30(17 \%)$ & $21(7 \%)$ & $82(25 \%)$ & $113(34 \%)$ & $49(15 \%)$ \\
Cluster 2 & $12(7 \%)$ & $67(22 \%)$ & $7(2 \%)$ & $7(2 \%)$ & $22(7 \%)$ \\
Cluster 3 & $30(17 \%)$ & $40(13 \%)$ & $52(16 \%)$ & $48(15 \%)$ & $108(32 \%)$ \\
Cluster 4 & $12(7 \%)$ & $39(13 \%)$ & $50(15 \%)$ & $31(9 \%)$ & $43(13 \%)$ \\
Cluster 5 & $15(9 \%)$ & $25(8 \%)$ & $19(6 \%)$ & $26(8 \%)$ & $37(11 \%)$ \\
Cluster 6 & $26(15 \%)$ & $41(13 \%)$ & $32(10 \%)$ & $67(20 \%)$ & $22(7 \%)$ \\
Cluster 7 & $34(19 \%)$ & $44(14 \%)$ & $46(14 \%)$ & $20(6 \%)$ & $33(10 \%)$ \\
Total & 174 & 308 & 328 & 333 & 332 \\
& & & & &
\end{tabular}


another word in the same data set, the number of possible topics rapidly increases with the size of the data set (Blei et al., 2003). Therefore, for practical and computational reasons, it is commonplace to delimit the number of topics into a manageable amount (Blei et al., 2003). What constitutes a manageable amount of topics depends on the query at hand, however, the choice of topics is not a crucial computational decision since each topic uses all the words in the data set - words in one topic are not excluded from other topics in the same model. In the spirit of large scale trend spotting, it was therefore thought that a topic model containing five topics would be suitable as it allows for several different probable topics, yet five topics is a manageable amount for manual and qualitative analysis. Following the same line of thought, it was decided to use a topics first eight words in the analysis, i.e. the eight words which have the highest probability to be associated.

One issue that has attracted attention is the enhanced stability of topic models as they operate on random seeding for the creation of probability distributions (Hornik and Grün, 2011). In effect, this means that topic models with the same number of topics, and modeling the same data set, will always deliver slightly different results (Hornik and Grün, 2011). In R, there is a possibility of running the same model several times on the same data set after which the best fit is presented - a function called nstart. Simplified, the more runs a topic model does the more stable the results. However, with the side effect of prolonged computation time. To strengthen the reliability of the topic modeling results it was decided that each topic model should run on the same data set with two different nstart values. After experimentation, it was decided that nstart 1,000 respectively 2,000 was a satisfactory combination as additional runs did not seem to have any substantial impact on the outcomes.

When it comes to the analysis and evaluation of topic models no machine learning models have yet outperformed that of human judgment even if steady progress is being made in the field (AlSumait et al., 2009; Dacres et al., 2013; Chang et al., 2009; Chemudugunta et al., 2008a, b; Wallach et al., 2009; Xie and Xing, 2013). Interpretation and evaluation was thus conducted by the author and is by nature subjective. The main advantage of this type of qualitative modus operandi is that it is fairly easy for someone with a general vocabulary to relatively quickly and efficiently interpret the context and implication of a generated topic. Czarniawska (2014) summarizes the issue by stating that many researchers have concluded that no software can interpret the collected field material and say "what it means" or "what it could mean", which creates the possibility of several competing or complementing interpretations or views. This interpretation is the researcher's prime responsibility.

\section{Results and trends in the data}

The results from the cluster modeling are shown in Table I. As mentioned in the methodological section, an eight cluster model was chosen as the final round of modeling. In this case the smallest cluster contained only 31 abstracts. Chopping up the data further by adding new clusters was hence deemed superfluous since clusters containing so few abstracts would make them unreliable for large scale trend identification, instead they would be zooming in on details. As clusters 3 and 4 together represented the majority of the data set (66 percent) they were further modeled into eight new clusters so that further analysis would be possible.

Figure 1, displays a visual representation of the final cluster modeling into eight clusters. From Table I and Figure 1, it is possible to conclude that a total of 1,475 abstracts, i.e. research articles, have been published between 1984 and 2014. Figure 1 shows that the edition has been fairly stable during the last 13 years, with a mean and median of 55 research articles annually and $\sigma=1.6$. Further Figure 1 shows that the journal peaked in 1995 with 68 articles and has an all-time low in 1986 with only 16 research articles published that year. The two years are linked as the period 1986-1995 show a clear trend with increasing publications each year until the highpoint of 1995.
Quality and reliability management

983 
IJQRM

34,7

984

Figure 1.

IJQRM 1984-2014 in 8 clusters

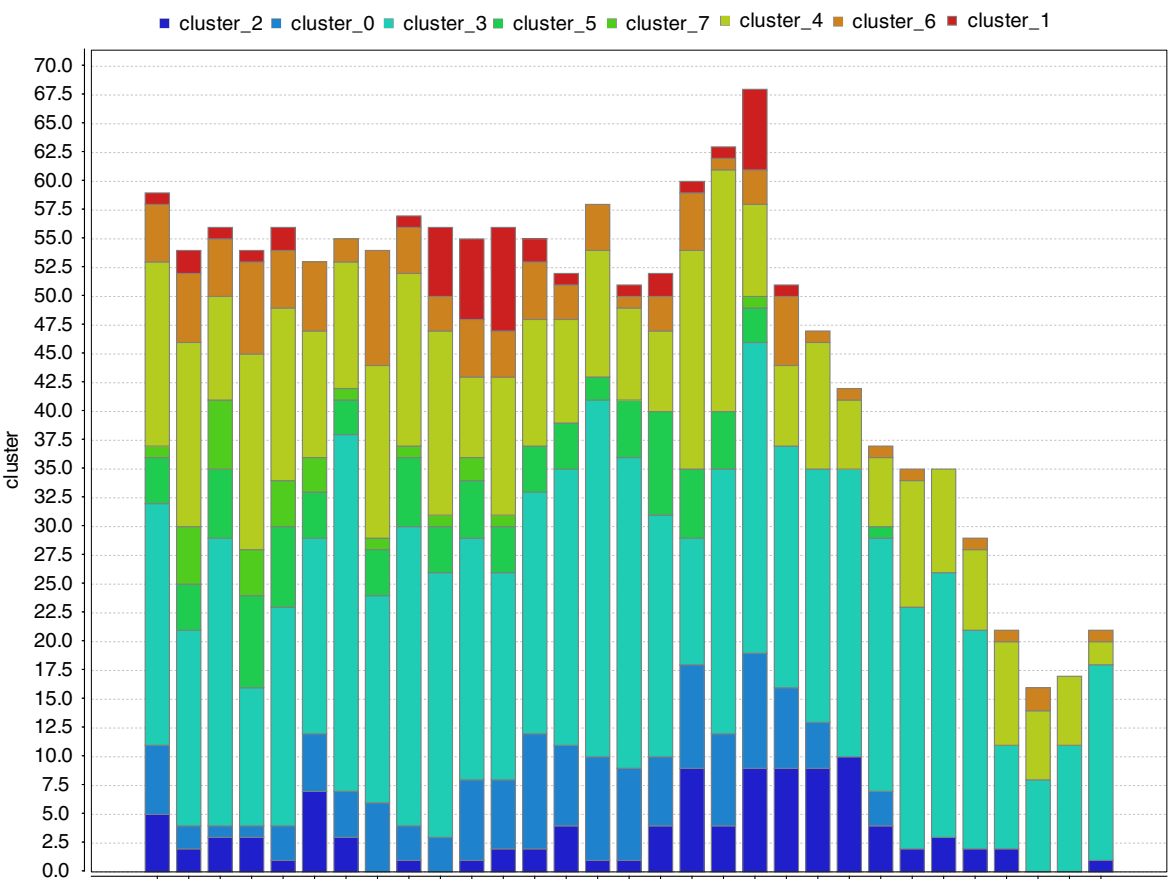

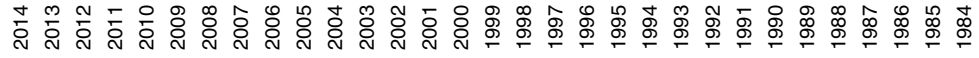

Year

The results obtained by topic modeling the eight clusters categorized in five topics, each with two different nstart values $(1,000$ and 2,000) can be viewed in Table AI. The eight clusters can, with the help of the generated topic models, be summarized in the following way:

(1) Cluster 0 (8 percent) - TQM and QM; mainly implementation and performance;

(2) Cluster 1 (3 percent) - QFD; design and development;

(3) Cluster 2 (7 percent) - processes; design, capability, control and charts;

(4) Cluster 3 (43 percent) - quality. A sub modeling into eight new clusters give:

- Cluster 0 (7 percent) - study of quality companies, quality manufacturing, quality software, business excellence organizations;

- Cluster 1 (7 percent) - QM practices;

- Cluster 2 (12 percent) - quality costs, supply chains and benchmarking;

- Cluster 3 (23 percent) - $\mathrm{QM}$; training programs, performance, systems improvement;

- Cluster 4 (13 percent) - quality design, quality methods, quality models and lean production;

- Cluster 5 (4 percent) - self assessment, EFQM, management assessment and the Kano model; 
- Cluster 6 (19 percent) - QM research; and

Quality and

- Cluster 7 (15 percent) - specific factors influencing quality; countries, management, environment.

(5) Cluster 4 (23 percent) - reliability and failure. A sub modeling into eight new clusters give:

- Cluster 0 (5 percent) - fuzzy methods, fuzzy reliability systems, maintainability robust design;

- Cluster 1 (16 percent) - reliability systems, production systems, processes and costs;

- Cluster 2 (7 percent) - sampling and inspection;

- Cluster 3 (5 percent) - software reliability;

- Cluster 4 (19 percent) - maintenance;

- Cluster 5 (9 percent) - failure and reliability; processes, systems and methodology;

- Cluster 6 (6 percent) - warranty and repairs; and

- Cluster 7 (33 percent) - reliability; models, data, methods and systems.

(6) Cluster 5 (7 percent) - ISO; standards, performance, certification, benefits; implementation;

(7) Cluster 6 (7 percent) - service quality; customer(s), SERVQUAL, relationships; dimensions; and

(8) Cluster 7 (2 percent) - Six Sigma (and lean to a small extent); innovation, strategies, performance, learning and improvement.

The results obtained by cluster modeling the five time series can be viewed in Table II.

The results obtained from modeling the five time intervals can be viewed in Table AII. As for the overall cluster modeling in Figure 1, stack bar charts for each time period were generated as exemplified in Figure 2 and showed in Figures A1-A4.

1984-1990:

- Cluster 0 (9 percent) - quality circles; QM and managers in Japan, quality programs;

- Cluster 1 (17 percent) - quality; QM, quality assurance, quality auditing, quality control;

- Cluster 2 (7 percent) - sampling and inspection;

- Cluster 3 (17 percent) - costs; quality costs, design cost, energy cost;

- Cluster 4 (7 percent) - service quality and system analysis;

- Cluster 5 (9 percent) - liability, safety, computer system problems, quality problems and makership;

- Cluster 6 (15 percent) - manufacturing (quality) and process control; and

- Cluster 7 (19 percent) - reliability and failure.

1991-1996:

- Cluster 0 (10 percent) - quality; customer satisfaction, costs and QFD;

- Cluster 1 (7 percent) - repair costs and probability; 
IJQRM

34,7

\section{6}

Figure 2.

IJQRM 1984-1990 structured into 8 clusters

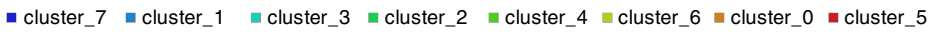

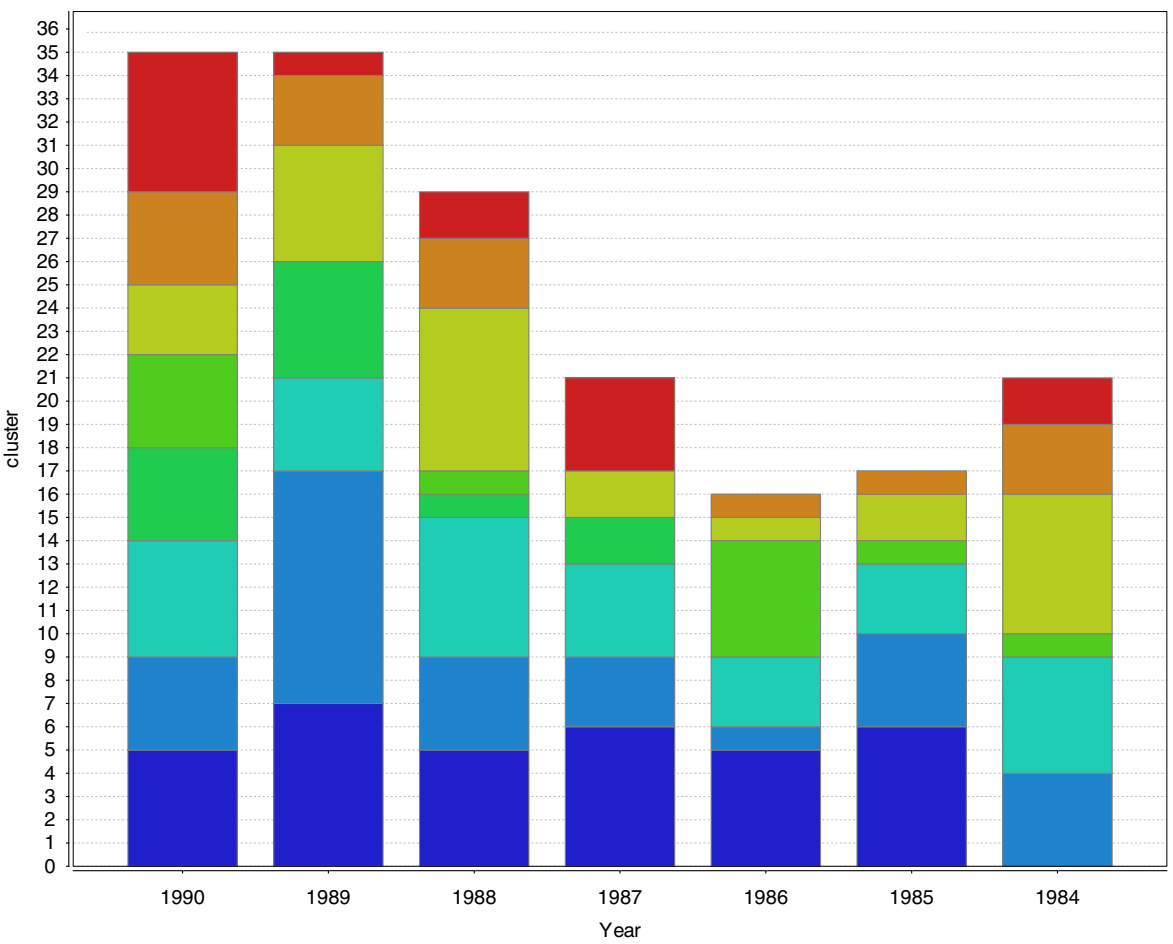

- Cluster 2 (22 percent) - QM; costs, quality construction;

- Cluster 3 (13 percent) - quality and process control;

- Cluster 4 (13 percent) - quality models, QM awards, ISO certification;

- Cluster 5 (8 percent) - production, productivity and maintenance;

- Cluster 6 (13 percent) - TQM; implementation; and

- Cluster 7 (14 percent) - reliability, failure, service quality and manufacturing. 1997-2002:

- Cluster 0 (12 percent) - ISO; certification, benefits, performance;

- Cluster 1 (25 percent) - QM; practices, models, projects and manufacturing;

- Cluster 2 (2 percent) - processes, statistical engineering and data quality;

- Cluster 3 (16 percent) - control; design and processes;

- Cluster 4 (15 percent) - service quality; customers, SERVQUAL, benchmarking;

- Cluster 5 (6 percent) - failure, repair, stress, sampling;

- Cluster 6 (10 percent) - reliability and self-assessment; and

- Cluster 7 (14 percent) - TQM; implementation, framework, employees. 
2003-2008:

- Cluster 0 (6 percent) - QFD;

- Cluster 1 (34 percent) - miscellaneous on cost, warranty, QM, etc.;

- Cluster 2 (2 percent) - Six Sigma; improvement, fad;

- Cluster 3 (15 percent) - TQM; performance and implementation;

- Cluster 4 (9 percent) - ISO; certification, implementation, practices;

- Cluster 5 (8 percent) - service quality; customer satisfaction, instruments, SERVQUAL;

- Cluster 6 (20 percent) - miscellaneous on maintenance, QM, quality models, process improvement, etc.; and

- Cluster 7 (6 percent) - failure and reliability.

2009-2014:

- Cluster 0 (5 percent) - control; charts, processes, design;

- Cluster 1 (15 percent) - service quality; customers, dimensions;

- Cluster 2 (7 percent) - Six Sigma and Lean; innovation, improvement, performance and learning;

- Cluster 3 (32 percent) - miscellaneous on quality, cost, performance, quality design, etc.;

- Cluster 4 (13 percent) - quality; QM, quality design, QMPS;

- Cluster 5 (11 percent) - TQM; performance, practices, self-assessment;

- Cluster 6 (7 percent) - reliability and failure; and

- Cluster 7 (10 percent) - ISO; implementation, performance and indicators.

The results show that $I J Q R M$ has had a stable edition profile during the last 20-year period after an initial ten-year period of growth. This development indicates that there existed a momentum for the type of research articles that the journal published during the 1980s and 1990s, which is why the issues and number of published papers steadily grew until reaching an equilibrium in the mid-1990s. Without taking indexing and ranking into account, this points toward IJQRM being a well-established and dependable scientific journal which sets the scene for profound and lasting academic debates over the covered research topics.

According to IJQRM itself the journal "deals with all aspects of business and manufacturing improvements, from the training of senior managers, to innovations in processing and production to raise standards of product quality". The results support this statement: the journal is indeed versatile and offers a multitude of topics. Nonetheless, it is also clear that IJQRM is firmly grounded in quality and reliability management as the majority of abstracts in the overall cluster modeling, as well as the partitioned time series, fall into these two categories. Hence, researchers, practitioners and stakeholders with an interest in publishing and taking part of research findings regarding quality and reliability management have a dependable platform for distributing and sharing knowledge. Other identifiable topics that emerge in IJQRM through clustering are TQM, service quality, QFD, ISO certification and Six Sigma. These could be seen as topics receiving extraordinarily high coverage in IJQRM and it would be acceptable to highlight them when marketing the journal, as is done with QFD. Of the named topics, service quality is seen as the one least marketed and communicated, it could thus be worth emphasizing it in future 
IJQRM

34,7

988

communication and information activities. The results clearly show continuous publication of service quality research articles and IJQRM is consequently justified in putting it forward as a key subject area. Accordingly, researchers focusing on service quality should not shed IJQRM but instead regard it as a well-grounded base for publication and knowledge retrieval.

Looking into the historical evolution of topics in IJQRM some variation between the chosen time periods can be noted. As the study explores for large scale trends, fashions, and fads small disparities within topics are not brought into focus, although it is feasible that the results could prove valuable for studies of more specific and rare topics. Starting in the 1980s there was a clear interest in quality circles as well as in Japanese manufacturing and management, after which it faded away. In contrast TQM appeared in 1991-1996 and has been a significant and reoccurring research topic right up until at least 2014. A similar journey can be identified for research on ISO, however, this initially broke through at a later time period, 1997-2002, after which it settled as reappearing topic. QFD has evolved somewhat differently, first showing up in 1991-1996 and then taking a leap into 2003-2008 where it constituted a cluster on its own, after which it fell into the background in 2009-2014. As a result, QFD could be classified as a topic in decline, or as a fading trend. In contrast, Six Sigma is shown as a topic on the rise, starting small in 2003-2008 and then coupled with lean growing in 2009-2014. Although only a possible indication of current trends, it may be worth noting that publications on reliability, failure and maintenance have decreased significantly during the last period of 2009-2014. In sum, researchers looking to publish in IJQRM could gain strategic benefits in the publication process by presenting research on Six Sigma and Lean and avoiding QFD, reliability, failure and maintenance.

An important result well worth reflecting on is the distribution of papers after cluster modeling; a tendency can be noticed for one or two large clusters to dominate while the other clusters represent a smaller and smaller portion of the total data set. The effect created is that of several distinct but small clusters and a few large ones which are hard to summarize and classify. A way of interpreting these results might be to argue that the abstracts become more and more coherent, i.e. they are harder to distinguish and classify for the clustering algorithm. This statement could be supported by the fact that a standard format for research paper abstracts in IJQRM was introduced in 2005, where all needed to contain: purpose, design/methodology/approach, findings, limitations, practical implications and originality/value. This change, surely with the intention of simplifying search and overview of abstracts, could well have led to a homogenization of abstracts which could prove to be a challenge for text mining with clustering algorithms. Clustering algorithms aim to identify similarities between objects, therefore it is natural that the outcome of a very homogenous material is a dominant cluster with a periphery of much smaller clusters, as even for homogenous data there is always some similarity between some objects in the data set, which then will be identified and grouped together. If this is true, other objects for identification and classification could prove better than abstracts, an obvious example being keywords. On the other hand, it would be unwise on the basis of these results to claim that the standardization of abstracts has a negative effect for text mining purposes as structure and coherence more often than not are positive in this regard. Conversely, yet still following this trail of thought, it is equally possible to argue that the research papers and their corresponding abstracts are actually more heterogeneous in later editions of IJQRM. Applying the same principle as above with a homogenous data set, it can be the case that even a much diversified data set will end up with few large clusters and several small but distinct clusters. However, in the latter case, the large clusters will be characterized by heterogeneity and not homogeneity. 
Finally, it can be noted that there is no clear-cut sign of IJQRM changing direction in 1998 due to the incorporation of the International Journal of Quality Science. This does not mean that there was no change in direction; however, it does show that the influence was modest and that the journal did not change its fundamental orientation.
Quality and reliability management

\section{Discussion}

Within the academic community there exists a debate regarding trends, fashion and fads in research (Abrahamson, 1996, 2009; Abrahamson and Eisenman, 2008; Abrahamson and Fairchild, 1999; Czarniawska, 2007, 2011a, 2014; Czarniawska and Panozzo, 2008; Parush, 2008; Starbuck, 2009; Trout, 2004). This study supports the claim that new topics and research areas are constantly introduced, indicating that there are indeed trends, fashion and fads in research. The study also shows that, in the case of IJQRM and the research it represents, there exists a stable nucleus covering quality and reliability management, which might be labeled the academic fields' core fashion or leading paradigm. However, the study cannot say anything about why or how new introductions or changes occur. The patterns could be explained by variables put forward by Czarniawska (2011a), Czarniawska and Panozzo (2008), Starbuck (2009) and Trout (2004), such as changes in the editorial board, new observations, experiences or interests in the academic community, alteration of financing and boredom. Additionally, considering the results it could be argued that established and fashionable terms such as quality or reliability management slowly become devalued due to inconsequential or frivolous usage. Subsequently, the terminologies become ill-defined, vague and all-encompassing rendering them unsuitable for research purposes. Conversely, researchers with a long-term commitment to quality and reliability management research might have an interest in actively reflecting upon their personal stand and influence on the fields epistemological development. If it is believed that the research area rests on a shaky theoretical base, it might be wise to prioritize terminological consistency and resist introduction and usage of new terminologies even if they increase the prospect of publication. Otherwise one renders the risk of contributing to the terminological inflation and further watering down the fields theoretical foundation. However, if one does not look upon the research field as weakly rooted in theory or publication is of high importance the results indicate that one should be cautious of fading stars, like QFD in this case, and instead prioritize topics on the rise, such as Six Sigma and lean in this study. For more detailed exploration of these kind of causes and effect-chains regarding trends in research, data mining studies like Dereli et al. (2011) are very complementary as they include supplementary information, e.g. name of writer, country of origin, university, etc. The combination of these two approaches could offer a way to identify the true driving forces behind trends that Czarniawska and Panozzo (2008) put forward as the main factors when new trends and fashions are launched.

This study supports the notion that QM as well as TQM gained an increasing amount of attention during the 1980s and 1990s as the number of publicized articles steadily grew, until the peak in 1995 after which the situation stabilized (Dahlgaard-Park, 1999, 2011; Dahlgaard-Park et al., 2013; Rocco and Parry, 2011; Sila and Ebrahimpour, 2002; Sousa and Voss, 2002; Van Der Wiele et al., 2000). Since the number of publications has stayed stable and has not decreased significantly this could be taken as proof of quality and reliability management as well as TQM, ISO and service quality being well-established fields of research that are here to stay, rather than transitory trends or fashions. Given the results from the overall cluster modeling (1984-2014) it might be tempting to label QM as the dominant paradigm or fashion, followed by reliability management, TQM, ISO and service quality. However, adding the chronological results, allows this order to be challenged. Essentially, by taking into account the possible effect of terminology devaluation, one could argue that quality and reliability management might have become too fuzzy and ambiguous, whereas TQM, ISO and service quality remain more distinct. If this is the case, TQM, ISO and service quality 
IJQRM

34,7

990

might actually be the current paradigms, fashions or trends, each having more of a delimiting and unifying ability than both quality and reliability management.

It must be reemphasized that the study only encompasses one scientific journal, using an exploratory and descriptive methodology, which make the results highly dependent on the specific data set and modeling. Therefore, there may exist many possible explanations for the specific observations presented in this study. This means that keyword search studies like Dahlgaard-Park et al. (2013) serve as an complementary perspective to the kind of research presented in this paper since they include a broader scope of publications, albeit, not as innate. Combining the two approaches would, hence, be a way of exploring both the findings of this study regarding QM as well as exploring how keywords and abstracts correspond to each other, thereby validating the statement by Delen and Crossland (2008), Miner (2012) and Weiss et al. (2012) that abstracts are a more trustworthy summary of a research article than its associated keywords.

One big setback of trying to organize abstracts through cluster modeling is the risk of identifying trends and fashion in writing, rather than changes in actual research; an effect that could have influence at both a micro and a macro level. On the micro-level it could well be that researchers interested in a specific topic have a very similar way of describing their work and results when writing abstracts. This could then lead to an increased probability for the clustering algorithm to classify these abstracts as similar and to group them together into a cluster, instead of forming a cluster of another topic that is actually bigger but where the writers express themselves less consistently. At the macro level this line of thought would favor cluster modeling on abstracts later on in IJQRM's publication history as they are standardized and, hence, would be easier to classify. As the results cannot be said to prove this point, it is interesting to reflect whether abstracts in the early days of IJQRM are actually better for cluster modeling as they are less uniform, displaying instead a diversity which makes them labor intensive for humans to look over and classify but easier for statistical and mathematical programs to work with.

\section{Conclusions}

This study supports the notion that there are trends in research, but as the results do not give any guidance as to the reasons behind these trends, complementary studies are needed. Topics identified by the study to be in decline are QFD and areas within the fields of reliability, failure and maintenance management. A topic on the rise is Six Sigma with a particular orientation toward lean, innovation, implementation and improvement.

The study supports quality and reliability management being the dominant fashion or trend in the covered academic field. However, the study also offers an alternative explanation discussing whether TQM, ISO and service quality might actually be the current paradigms and fashions in the field as they have remained more distinct, thus being less watered down than quality and reliability management.

The results verify the statement of $I J Q R M$ being a journal "dealing with all aspects of business and manufacturing improvements" with specific coverage of quality and reliability management as well as:

- TQM;

- Service quality;

- ISO;

- Process management;

- QFD; and

- Six Sigma. 
Finally, the study propels further examination of cluster and topic modeling for both epistemological pursuits as well as for BI purposes, as these approaches offer a useful way of exploring and describing large quantities of unstructured data.

\section{Future research}

The collected data could be re-used but processed with different cluster-models as well as on the basis of other word vectors, e.g. term frequency. This would give an interesting view of how the document matrix affects the clustering and their content. Yet another angle would be to explore supervised learnings models, alternatively one could filter the data set for a specific topic, e.g. ISO, and subsequently model with this material, giving a detailed insight of a specific topic and its evolution over time.

\section{Limitations}

The study focuses on research article abstracts. Other journal content such as book reviews, general reviews, secondary articles, editorials, guest editorials, awards for excellence (notifications), introductions or summaries from conferences, notes from the publisher and articles without an abstract are not a part of the study which may exclude certain topics and trends.

\section{References}

Abrahamson, E. (1996), "Management fashion", Academy of Management Review, Vol. 21 No. 1, pp. 254-285.

Abrahamson, E. (2009), "Necessary conditions for the study of fads and fashions in science", Scandinavian Journal of Management, Vol. 25 No. 2, pp. 235-239.

Abrahamson, E. and Eisenman, M. (2008), "Employee-management techniques: transient fads or trending fashions?”, Administrative Science Quarterly, Vol. 53 No. 4, pp. 719-744.

Abrahamson, E. and Fairchild, G. (1999), "Management fashion: lifecycles, triggers, and collective learning processes", Administrative science quarterly, Vol. 44 No. 4, pp. 708-740.

Aggarwal, C.C. and Zhai, C. (Eds) (2012), Mining Text Data, Springer Science \& Business Media, New York, NY.

AlSumait, L., Barbará, D., Gentle, J. and Domeniconi, C. (2009), "Topic significance ranking of LDA generative models", Joint European Conference on Machine Learning and Knowledge Discovery in Databases, Springer, Berlin, Heidelberg, pp. 67-82.

Arthur, D. and Vassilvitskii, S.G.H. (2007), "k-means++: the advantages of careful seeding", SODA '07 Proceedings of the Eighteenth Annual ACM-SIAM Symposium on Discrete Algorithms, pp. 1027-1035.

Becher, T. and Trowler, P.R. (2001), Academic Tribes and Territories: Intellectual Enquiry and the Culture of Disciplines, 2nd ed., Open University Press, Philadelphia, PA.

Blei, D. (2012), "Probabilistic topic models", Communications of the ACM, Vol. 55 No. 4, pp. 77-84.

Blei, D.M., Ng, A.Y. and Jordan, M.I. (2003), "Latent Dirichlet allocation”, Journal of Machine Learning Research, Vol. 3, pp. 993-1022, available at: www.jmlr.org/papers/v3/

Chakrabarti, S. (2003), Mining the Web: Discovering Knowledge from Hypertext Data, Morgan Kaufmann, Amsterdam.

Chang, J., Gerrish, S., Wang, C., Boyd-Graber, J.L. and Blei, D.M. (2009), "Reading tea leaves: how humans interpret topic models", Advances in Neural Information Processing Systems, Vancouver, December 7-10, pp. 288-296. 
IJQRM

34,7

992

Chemudugunta, C., Smyth, P. and Steyvers, M. (2008a), "Combining concept hierarchies and statistical topic models", Proceedings of the 17th ACM Conference on Information and Knowledge Management, ACM, pp. 1469-1470.

Chemudugunta, C., Smyth, P. and Steyvers, M. (2008b), "Text modeling using unsupervised topic models and concept hierarchies. arXiv:0808.0973 [cs.AI]".

Choudhary, A.K., Oluikpe, P.I., Harding, J.A. and Carrillo, P.M. (2009), "The needs and benefits of text mining applications on post-project reviews", Computers in Industry, Vol. 60 No. 9, pp. 728-740.

Czarniawska, B. (2007), "Has organization theory a tomorrow?", Organization Studies, Vol. 28 No. 1, pp. 27-29.

Czarniawska, B. (2011a), "Introduction to the special themed section: fashion in research and in management”, Organization Studies, Vol. 32 No. 5, pp. 599-602.

Czarniawska, B. (2011b), "Successful research: in whose eyes?”, European Accounting Review, Vol. 20 No. 1 , pp. 53-55.

Czarniawska, B. (2014), Ute på fältet, inne vid skrivbordet. (1. uppl.), Studentlitteratur, Lund.

Czarniawska, B. and Panozzo, F. (2008), "Trends and fashions in management studies (I): fashion in research”, International Studies of Management \& Organization, Vol. 38 No. 1, pp. 3-12.

Dacres, S., Haddadi, H. and Purver, M. (2013), “Topic and sentiment analysis on OSNs: a case study of advertising strategies on twitter", arXiv preprint arXiv:1312.6635.

Dahlgaard-Park, S.M. (1999), "The evolution patterns of quality management: some reflections on the quality movement”, Total Quality Management, Vol. 10 Nos 4-5, pp. 473-480.

Dahlgaard-Park, S.M. (2011), "The quality movement - where are you going?", Total Quality Management \& Business Excellence, Vol. 22 No. 5, pp. 493-516.

Dahlgaard-Park, S.M., Chen, C.K., Jang, J.Y. and Dahlgaard, J.J. (2013), “Diagnosing and prognosticating the quality movement - a review on the 25 years quality literature (1987-2011)", Total Quality Management \& Business Excellence, Vol. 24 Nos 1-2, pp. 1-18.

Delen, D. and Crossland, M.D. (2008), "Seeding the survey and analysis of research literature with text mining", Expert Systems with Applications, Vol. 34 No. 3, pp. 1707-1720.

Deming, W.E. (1986), Out of the Crisis, Cambridge University Press, Cambridge.

Dereli, T., Durmuşoğlu, A., Delibaş, D. and Avlanmaz, N. (2011), "An analysis of the papers published in Total Quality Management \& Business Excellence from 1995 through 2008”, Total Quality Management \& Business Excellence, Vol. 22 No. 3, pp. 373-386, doi: 10.1080/14783363.2010.532337.

Finch, B.J. (1999), "Internet discussions as a source for consumer product customer involvement and quality information: an exploratory study", Journal of Operations Management, Vol. 17 No. 5, pp. 535-556.

Garfield, E., Pudovkin, A.I. and Istomin, V.S. (2003), "Why do we need algorithmic historiography?", Journal of the American Society for Information Science and Technology, Vol. 54 No. 5, pp. 400-412.

Glenisson, P., Glänzel, W., Janssens, F. and De Moor, B. (2005), "Combining full text and bibliometric information in mapping scientific disciplines", Information Processing \& Management, Vol. 41 No. 6, pp. 1548-1572.

Hair, J.F., Black, W.C., Babin, B.J., Anderson, R.E. and Tatham, R.L. (2014), Multivariate Data Analysis, 7th ed., Pearson Education Limited, Essex.

Heim, G.R. and Field, J.M. (2007), "Process drivers of e-service quality: analysis of data from an online rating site", Journal of Operations Management, Vol. 25 No. 5, pp. 962-984.

Hornik, K. and Grün, B. (2011), "Topicmodels: an R package for fitting topic models", Journal of Statistical Software, Vol. 40 No. 13, pp. 1-30. 
Jain, A.K. (2010), "Data clustering: 50 years beyond K-means”, Pattern Recognition Letters, Vol. 31 No. 8, pp. 651-666.

Kent, E.L. (2014), "Text analytics - techniques, language and opportunity”, Business Information Review, Vol. 31 No. 1, pp. 50-53.

Khamis, N., Rilling, J. and Witte, R. (2013), "Assessing the quality factors found in in-line documentation written in natural language: the JavadocMiner", Data \& Knowledge Engineering, Vol. 87, pp. 19-40, available at: www.sciencedirect.com/science/journal/0169023X/87

Quality and reliability management

Köksal, G., Batmaz, İ. and Testik, M.C. (2011), "A review of data mining applications for quality improvement in manufacturing industry", Expert Systems with Applications, Vol. 38 No. 10, pp. 13448-13467.

Kurgan, L.A. and Musilek, P. (2006), "A survey of knowledge discovery and data mining process models", The Knowledge Engineering Review, Vol. 21 No. 1, pp. 1-24.

Larose, D.T. (2005), Discovering Knowledge in Data an Introduction to Data Mining, Wiley-Interscience, Hoboken, NJ.

Liu, B. (2011), Web Data Mining: Exploring Hyperlinks, Contents, and Usage Data, 2nd ed., Springer, Heidelberg.

Lo, S. (2008), "Web service quality control based on text mining using support vector machine", Expert Systems with Applications, Vol. 34 No. 1, pp. 603-610.

Marbán, O., Mariscal, G. and Segovia, J. (2009), “A data mining \& knowledge discovery process model. Data mining and knowledge discovery", in Ponce, J. and Karahoca, A. (Eds), Real Life Applications, February, I-Tech, Vienna, pp. 1-18.

Meeks, E. and Weingart, S. (2012), "The digital humanities contribution to topic modeling”, Journal of Digital Humanities, Vol. 2 No. 1, pp. 1-6.

Mimno, D. (2012), "Computational historiography: data mining in a century of classics journals", Journal on Computing and Cultural Heritage, Vol. 5 No. 1, pp. 1-19.

Miner, G. (red.) (2012), Practical Text Mining and Statistical Analysis for Non-Structured Text Data Applications, 1st ed., Academic Press, Waltham, MA.

Moro, S., Cortez, P. and Rita, P. (2015), "Business intelligence in banking: a literature analysis from 2002 to 2013 using text mining and latent Dirichlet allocation", Expert Systems with Applications, Vol. 42 No. 3, pp. 1314-1324.

Newman, D., Asuncion, A., Smyth, P. and Welling, M. (2009), "Distributed algorithms for topic models", Journal of Machine Learning Research, Vol. 10, pp. 1801-1828, available at: www.jmlr.org/ papers/v10/

Newman, D., Chemudugunta, C., Smyth, P. and Steyvers, M. (2006), "Analyzing entities and topics in news articles using statistical topic models", International Conference on Intelligence and Security Informatics, Springer, Berlin, Heidelberg, pp. 93-104.

Parush, T. (2008), "From 'management ideology' to 'management fashion': a comparative analysis of two key concepts in the sociology of management knowledge", International Studies of Management \& Organization, Vol. 38 No. 1, pp. 48-70.

Rocco, J.P. and Parry, G.J. (2011), "The epistemology of quality improvement: it's all Greek”, BMJ Quality \& Safety (2044-5415), Vol. 20 No. 1, pp. i24-i27.

Rosen-Zvi, M., Chemudugunta, C., Griffiths, T., Smyth, P. and Steyvers, M. (2010), "Learning author-topic models from text corpora", ACM Transactions on Information Systems, Vol. 28 No. 1, pp. 1-38.

Sila, I. and Ebrahimpour, M. (2002), "An investigation of the total quality management survey based research published between 1989 and 2000: a literature review", International Journal of Quality \& Reliability Management, Vol. 19 No. 7, pp. 902-970.

Sousa, R. and Voss, C. (2002), "Quality management re-visited: a reflective review and agenda for future research", Journal of Operations Management, Vol. 20 No. 1, pp. 91-109. 
IJQRM

34,7

994
Starbuck, W.H. (2009), "The constant causes of never-ending faddishness in the behavioral and social sciences", Scandinavian Journal of Management, Vol. 25 No. 1, pp. 108-116.

Stuti, K. and Veenu, M. (2013), "Evaluation of text document clustering approach based on particle swarm optimization”, Central European Journal of Computer Science, Vol. 3 No. 2, pp. $69-90$.

Trout, J.D. (2004), “The philosophical legacy of Meehl (1978): confirmation theory, theory quality, and scientific epistemology", Applied and Preventive Psychology, Vol. 11 No. 1, pp. 73-76.

Van Der Wiele, A., Williams, A.R.T. and Dale, B.G. (2000), "Total quality management: is it a fad, fashion, or fit?", ASQ Quality Management Journal, Vol. 7 No. 2, pp. 65-79.

Wallach, H.M., Murray, I., Salakhutdinov, R. and Mimno, D. (2009), "Evaluation methods for topic models", Proceedings of the 26th Annual International Conference on Machine Learning, ACM, June, pp. 1105-1112.

Weiss, S.M., Indurkhya, N. and Zhang, T. (2012), Fundamentals of Predictive Text Mining, Springer London, London.

Welling, M., Chemudugunta, C. and Sutter, N. (2008), "Deterministic latent variable models and their pitfalls", Proceedings of the 2008 SIAM International Conference on Data Mining, Society for Industrial and Applied Mathematics, Atlanta, GA, April 24-26, pp. 196-207.

Xie, P. and Xing, E. (2013), "Integrating document clustering and topic modeling", Uncertainty in Artificial Intelligence - Proceedings of the Twenty-Ninth Conference, Bellevue, WA, July 11-15.

\section{Further reading}

Nair, A. (2006), "Meta-analysis of the relationship between quality management practices and firm performance - implications for quality management theory development", Journal of Operations Management, Vol. 24 No. 6, pp. 948-975. 


\section{Appendix 1}

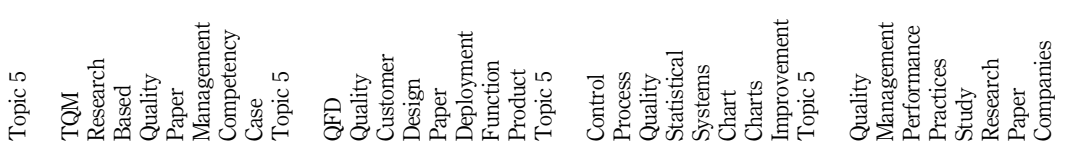

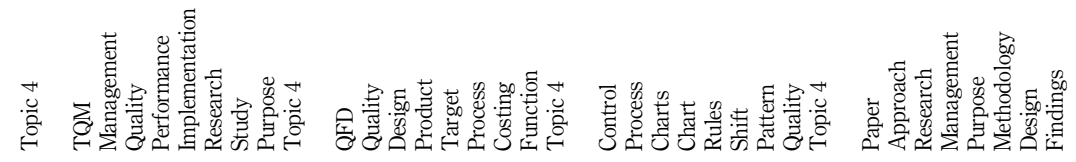

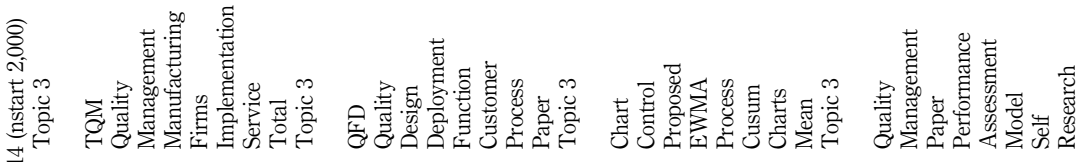

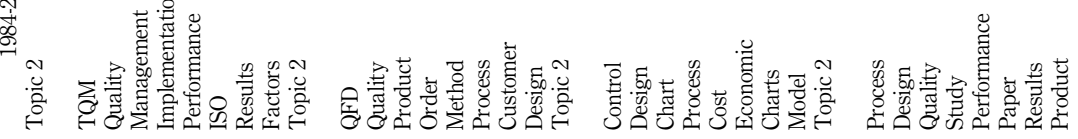

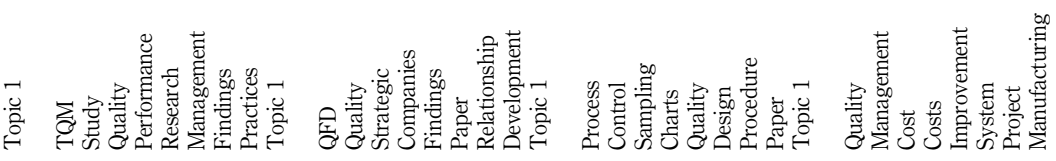

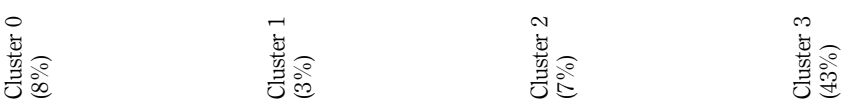

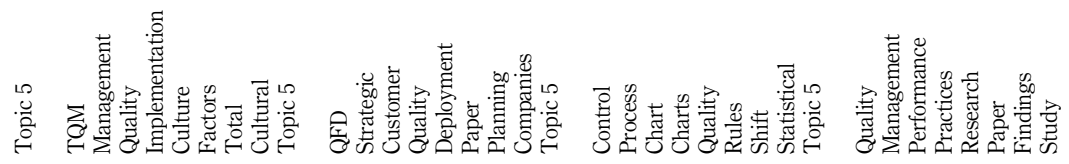

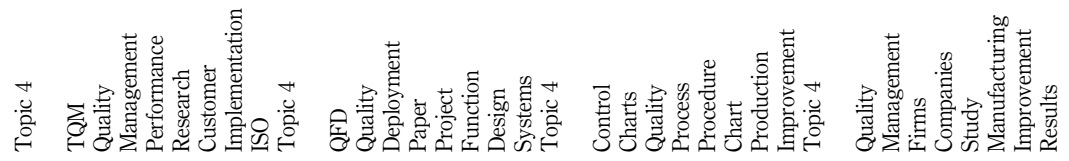

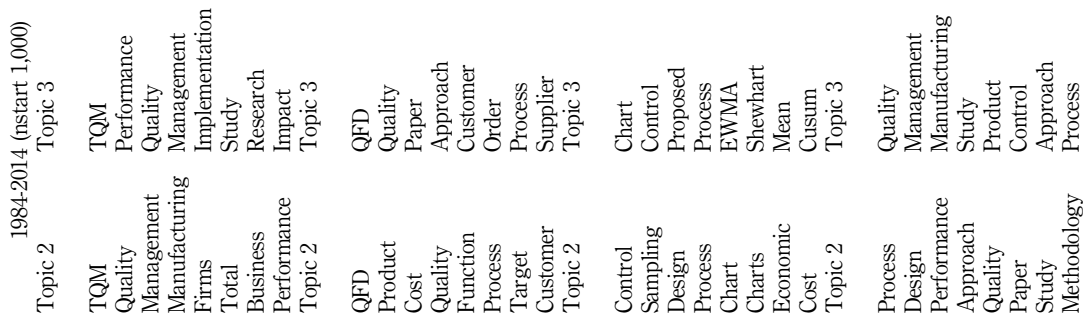

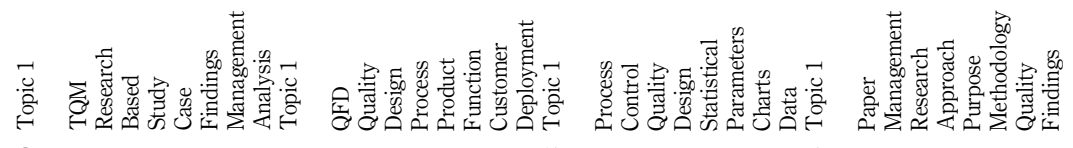
章路
尊
Quality and

reliability management

995
Table AI. Results from topic modeling the overall data set (IJQRM 1984-2014) 


\section{IJQRM \\ 34,7}

996

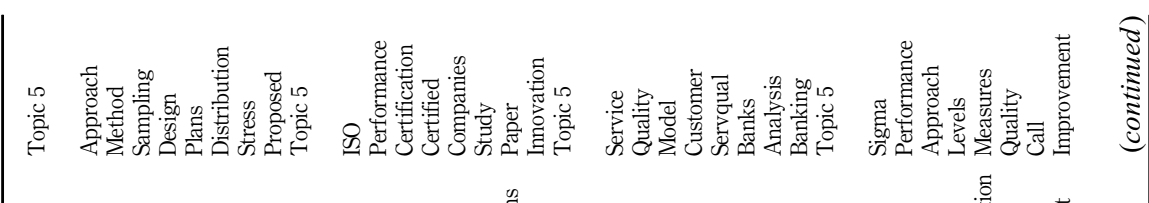

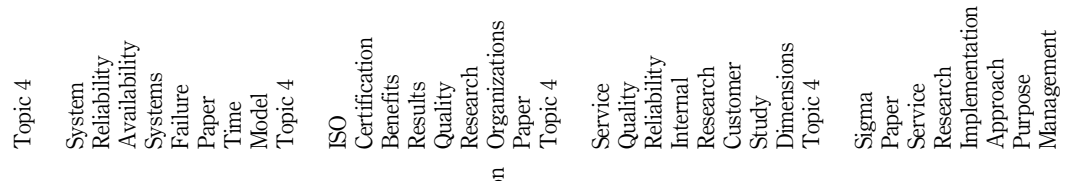

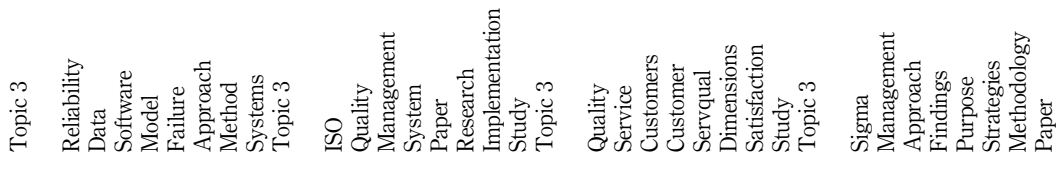

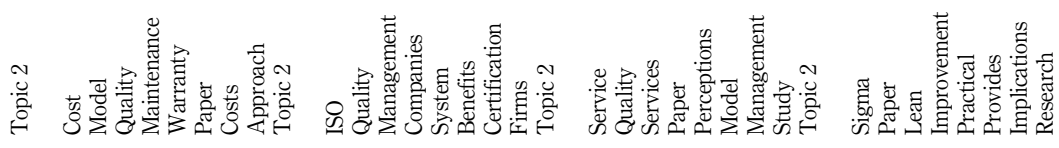

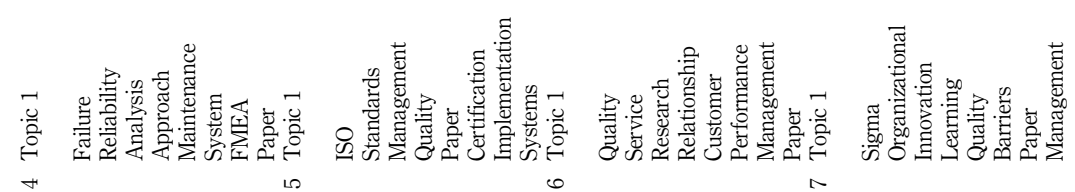

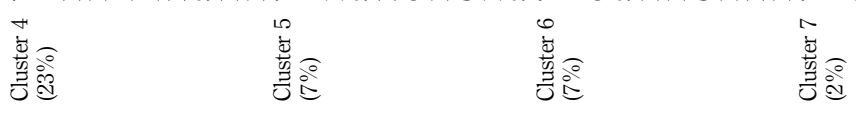

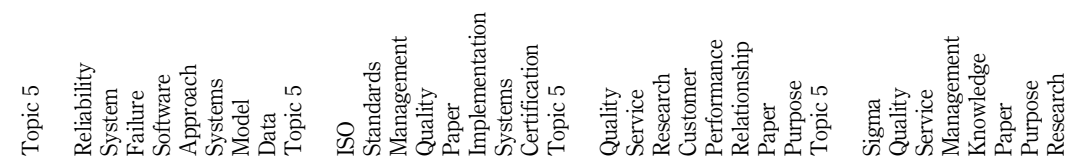

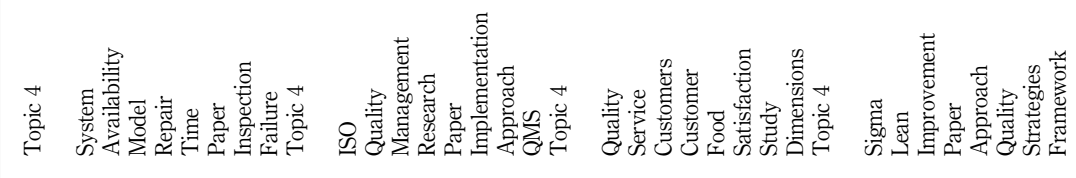

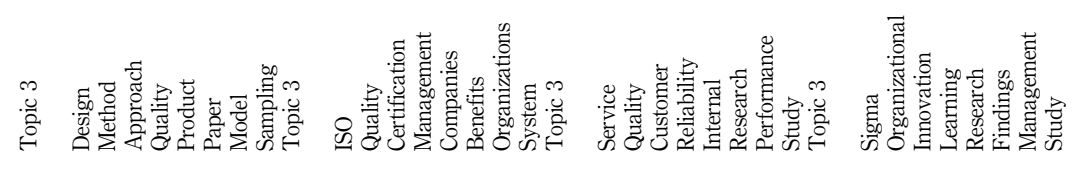

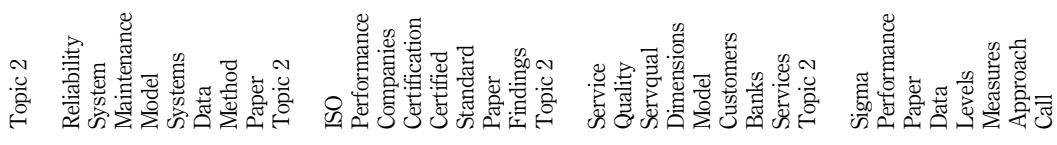

Table AI.

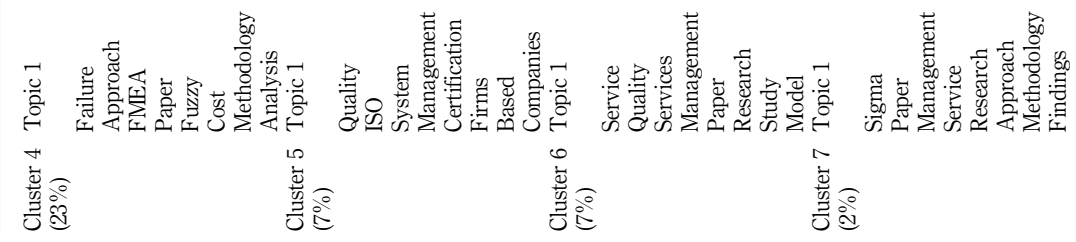





\section{IJQRM \\ 34,7}

998

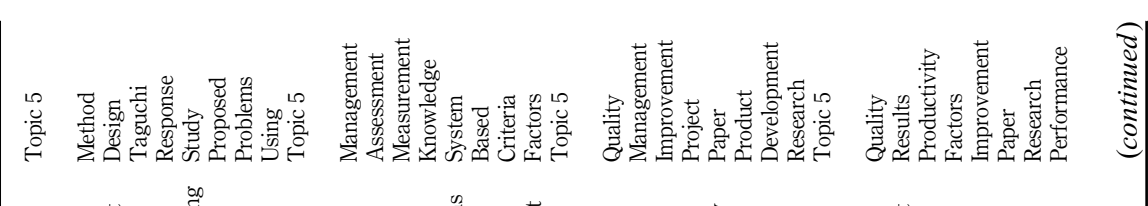

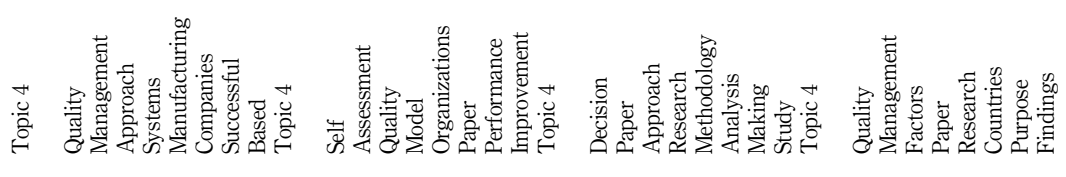

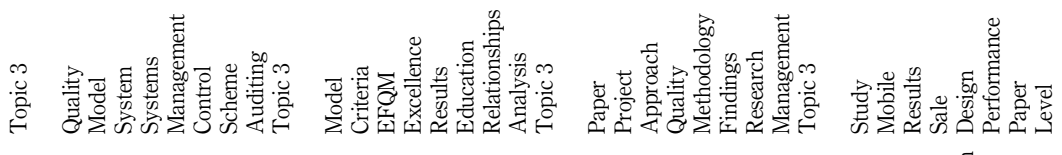

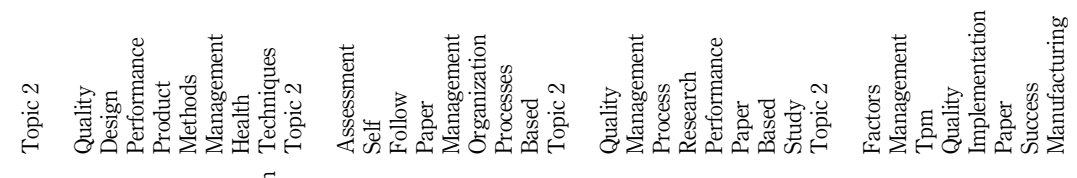

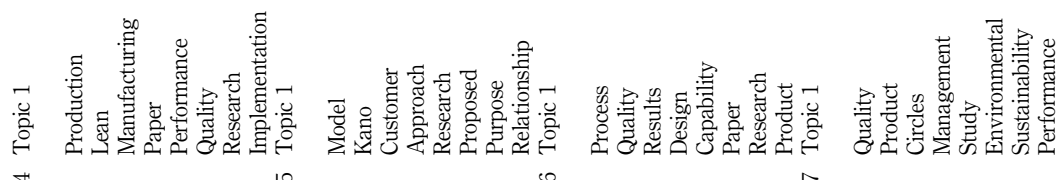

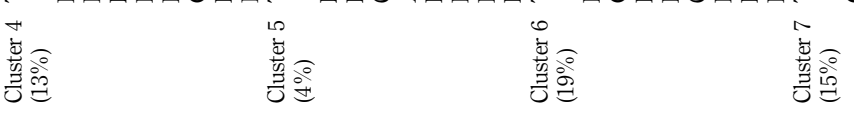

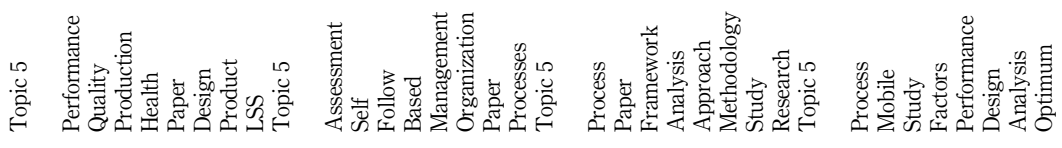

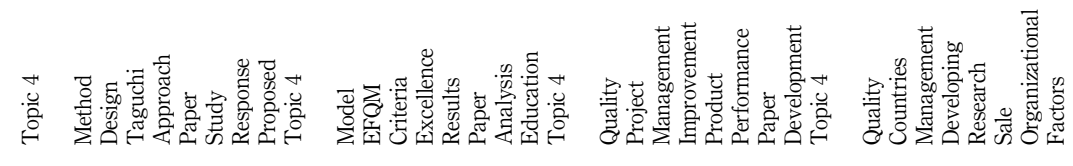

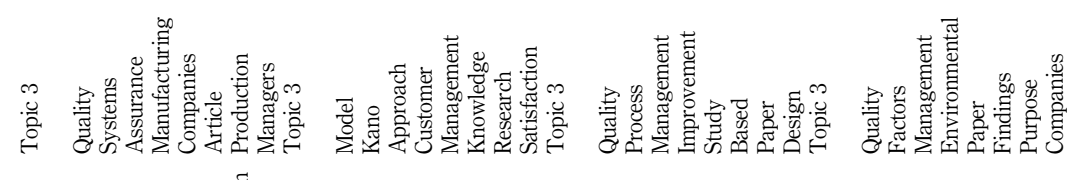

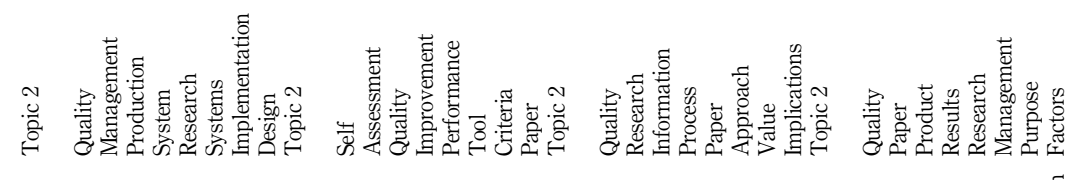

Table AI.

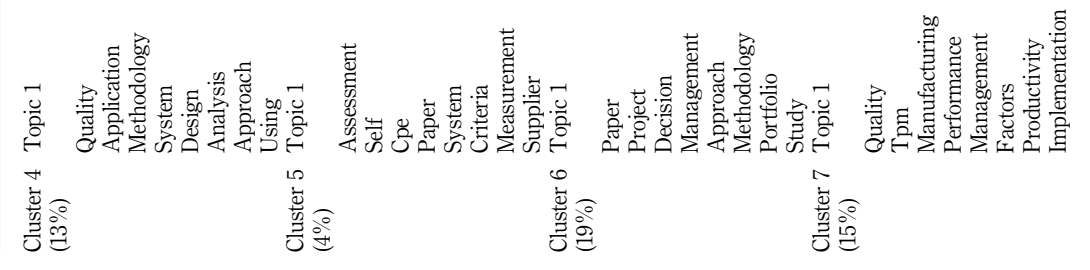





\section{IJQRM}

34,7

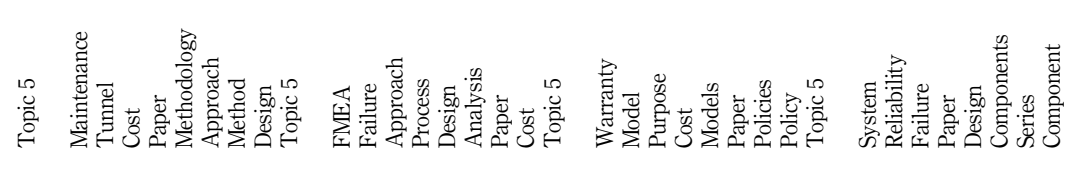

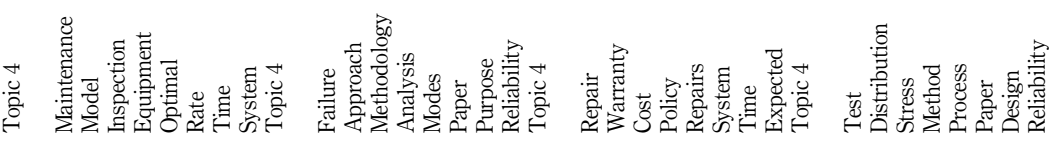

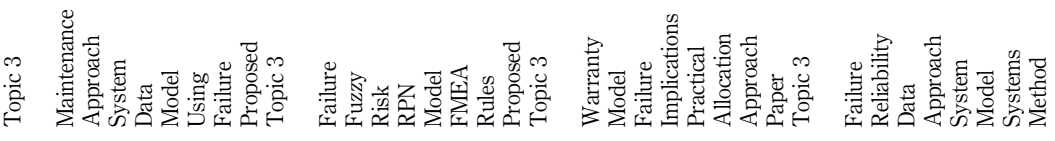

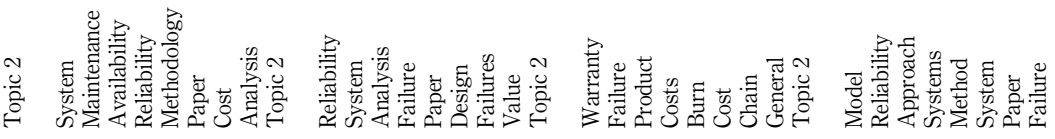

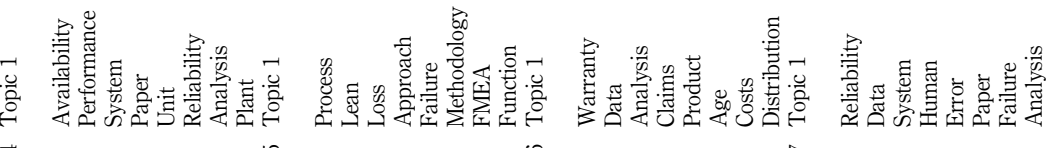

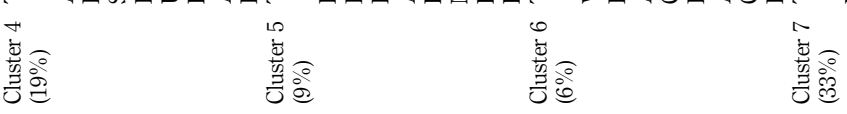

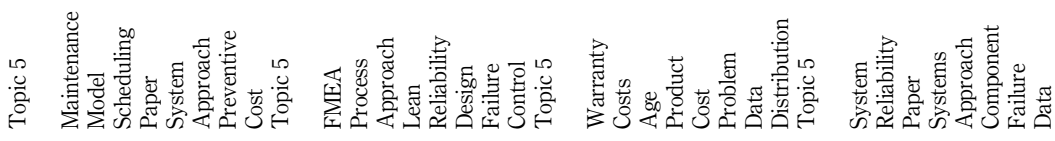

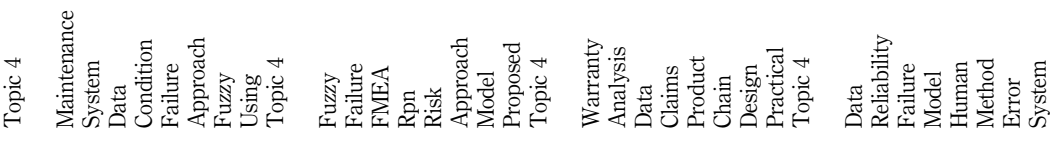

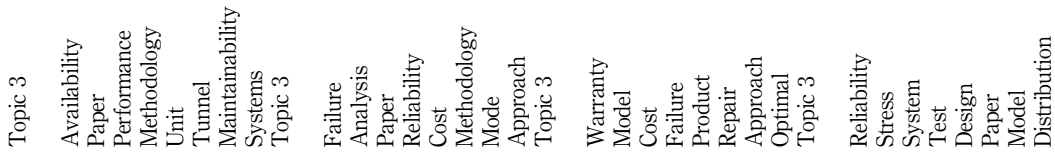
Table AI.

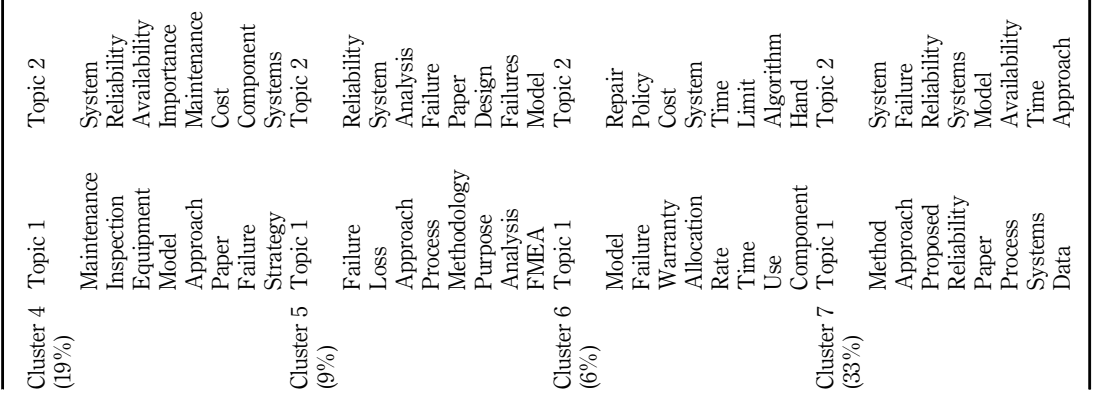




\section{Appendix 2}

Quality and

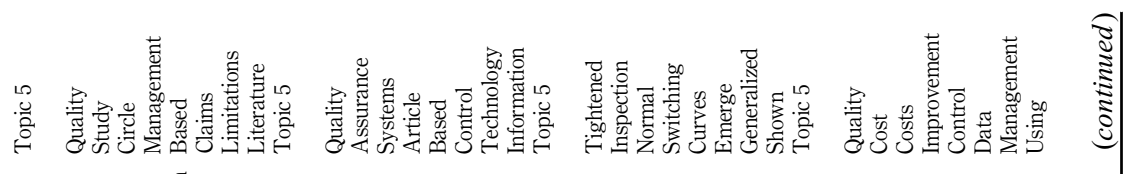
reliability management

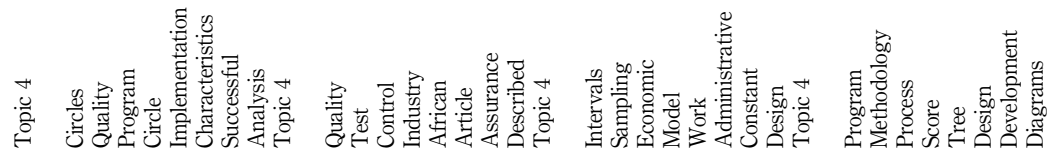

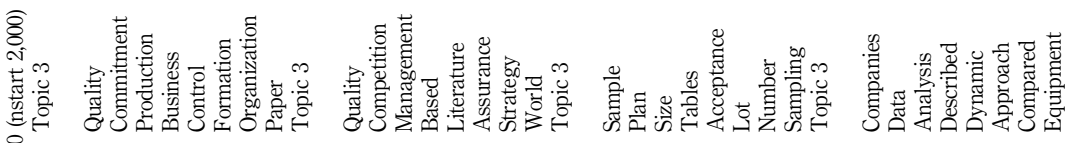

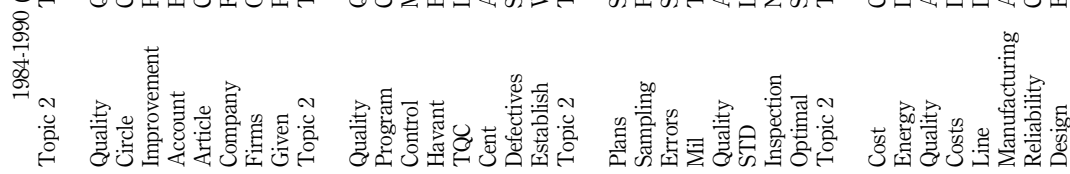

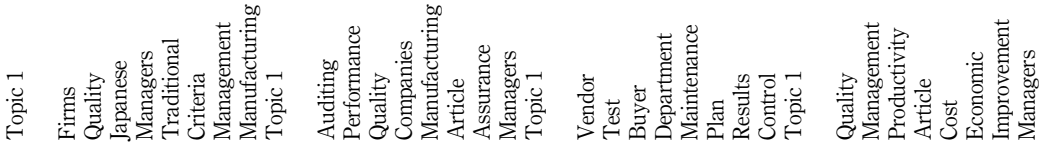

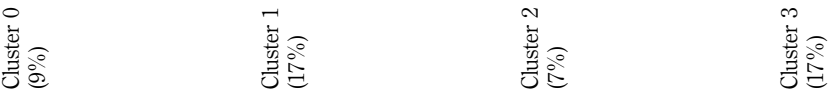

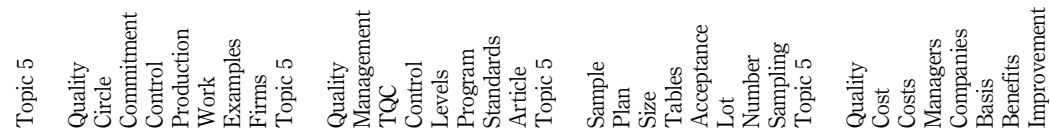

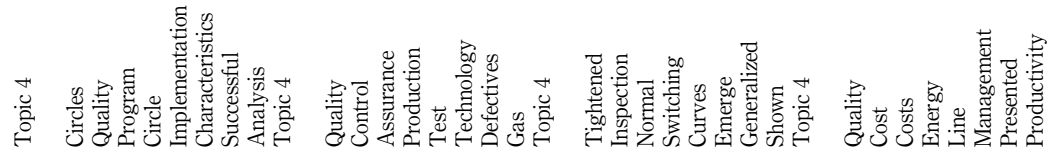

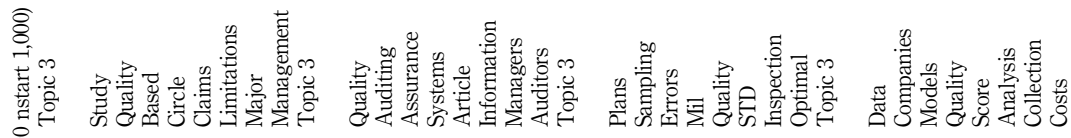
总

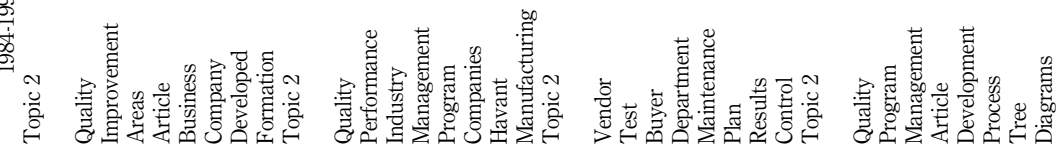

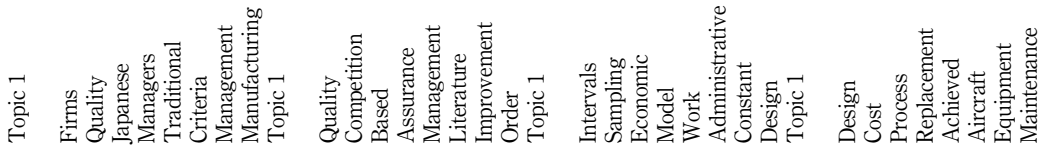

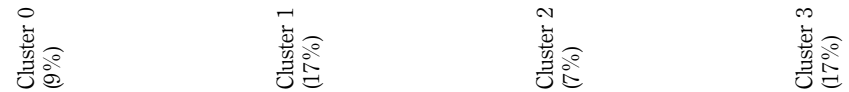

Table AII. Results from topic modeling the divided data set (IJQRM 19841990, 1991-1996, 19972002, 2003-2008 and 2009-2014) 


\section{IJQRM \\ 34,7}

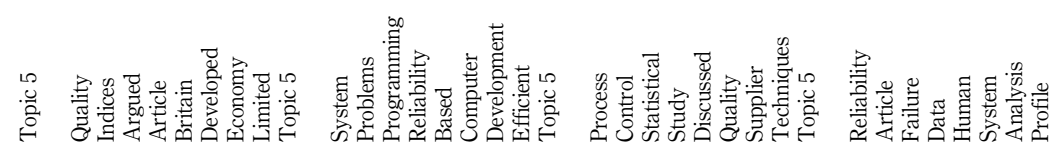

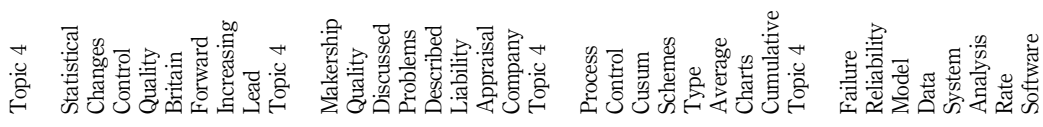

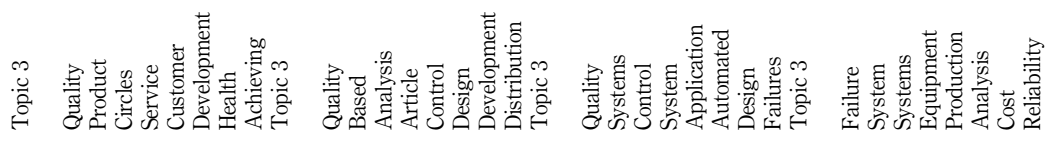

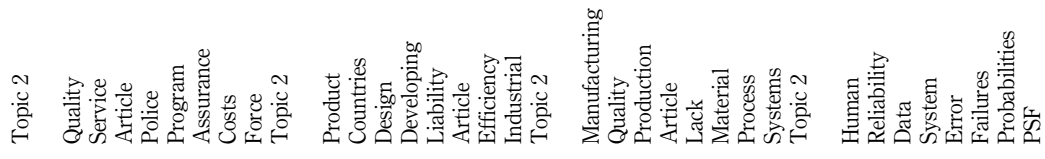

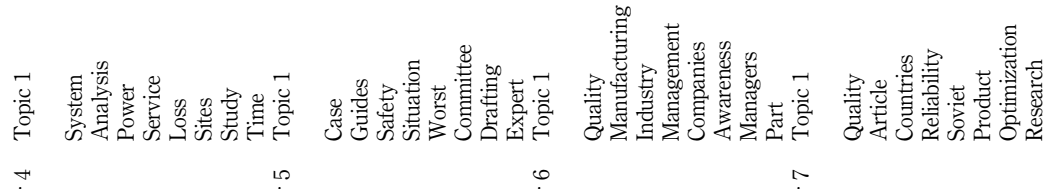

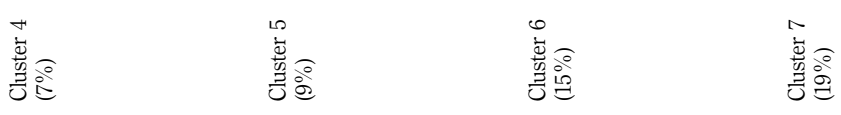

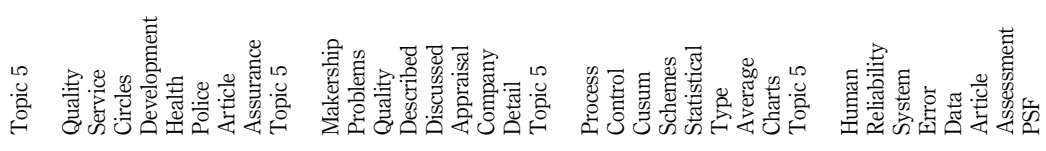

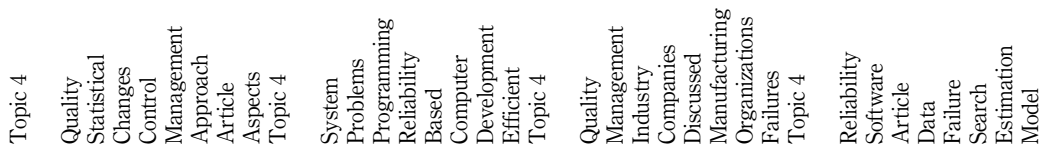

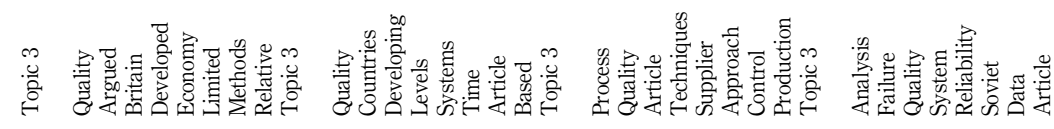

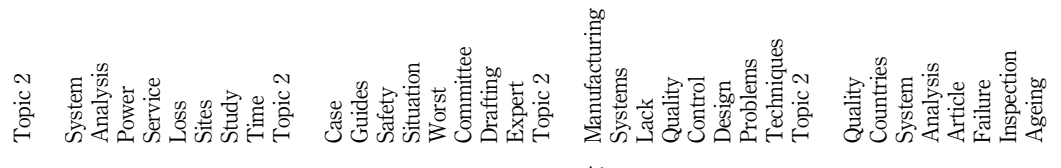

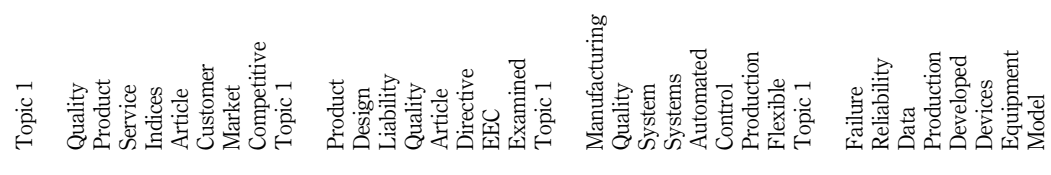

Table AII.

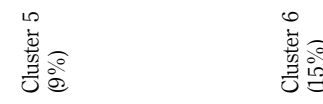
管 



\section{IJQRM \\ 34,7}

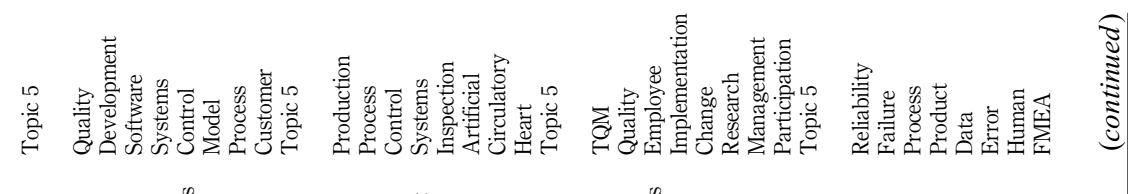

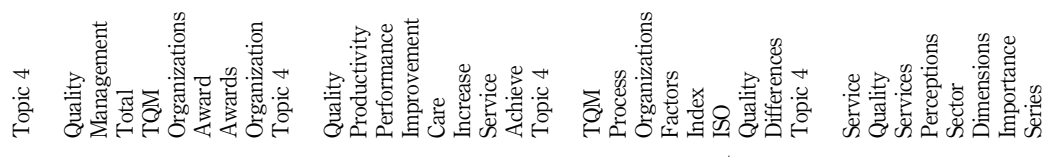

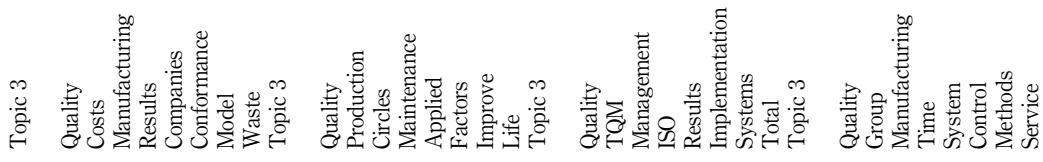

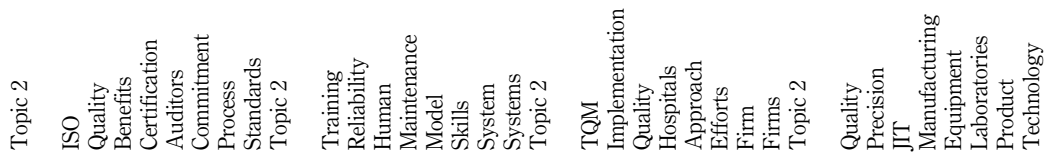

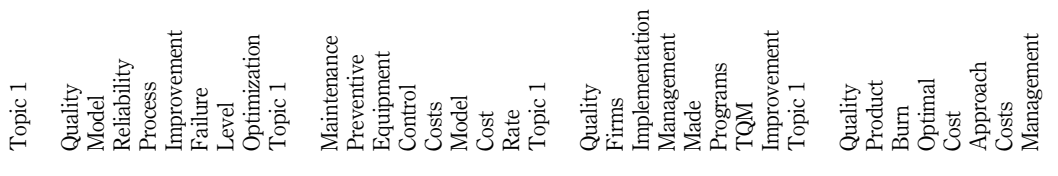

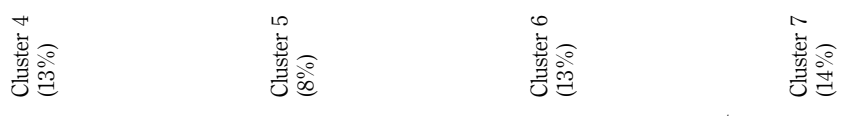

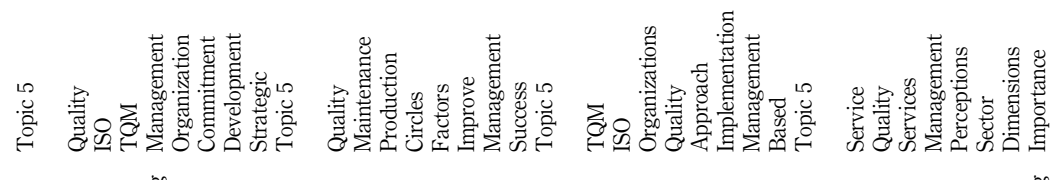

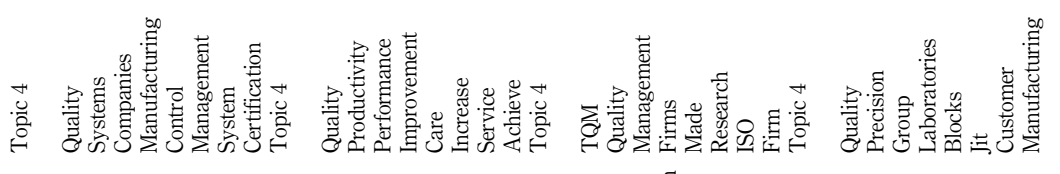

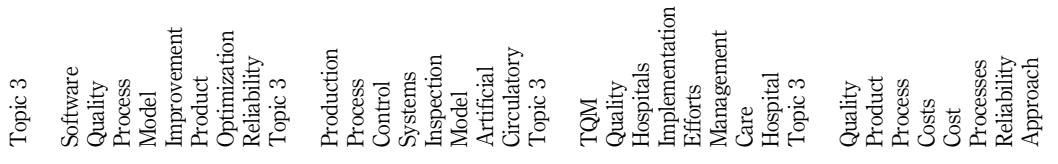

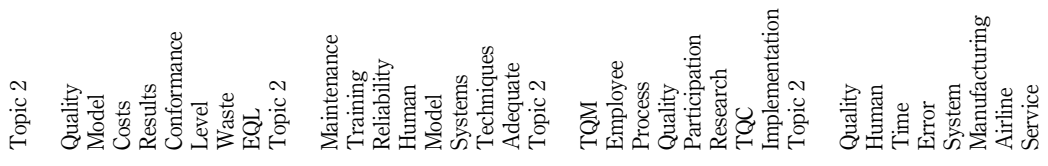

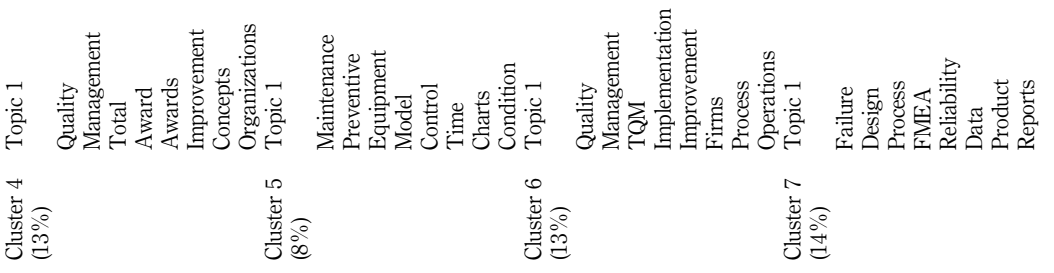

Table AII. 



\section{IJQRM}

34,7

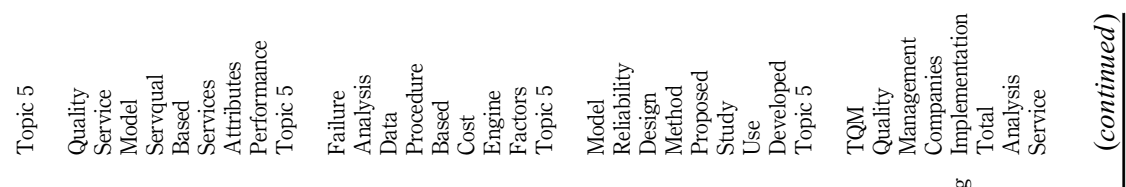

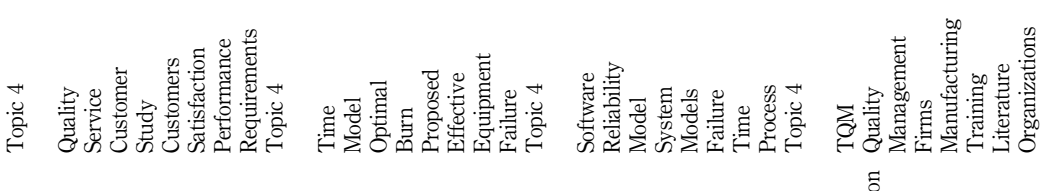

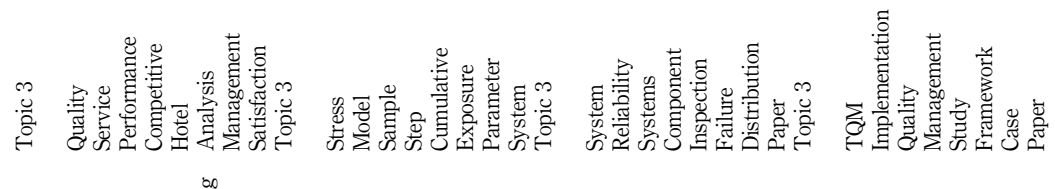

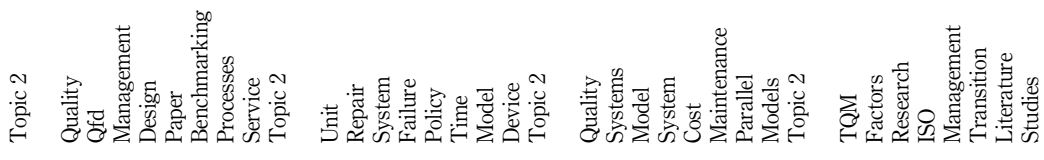

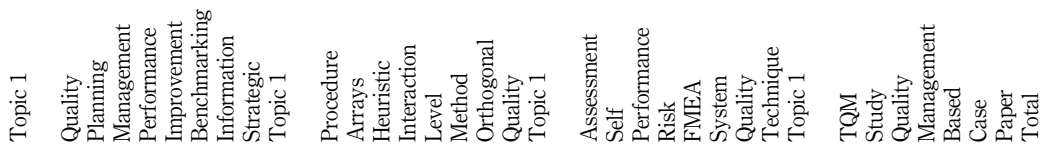

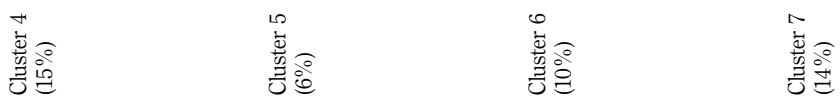

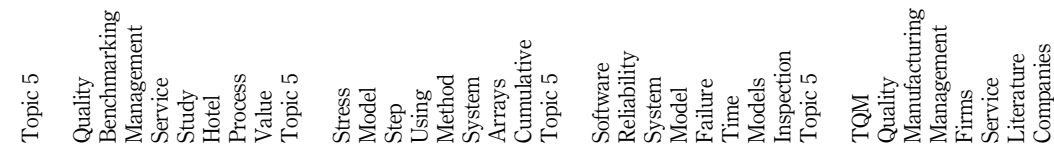

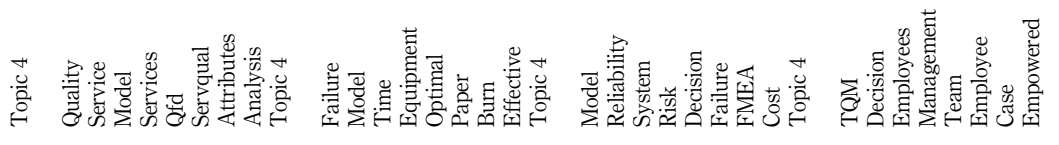

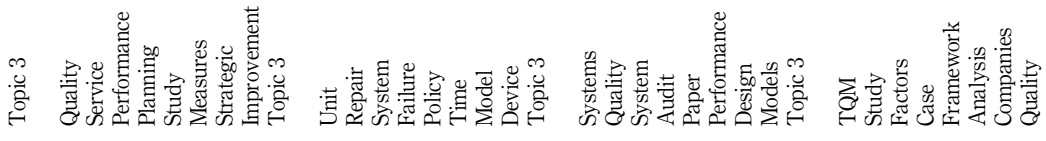

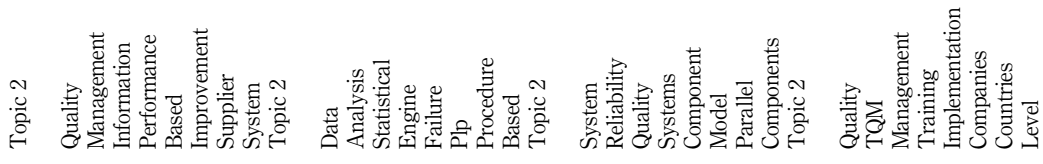

Table AII.

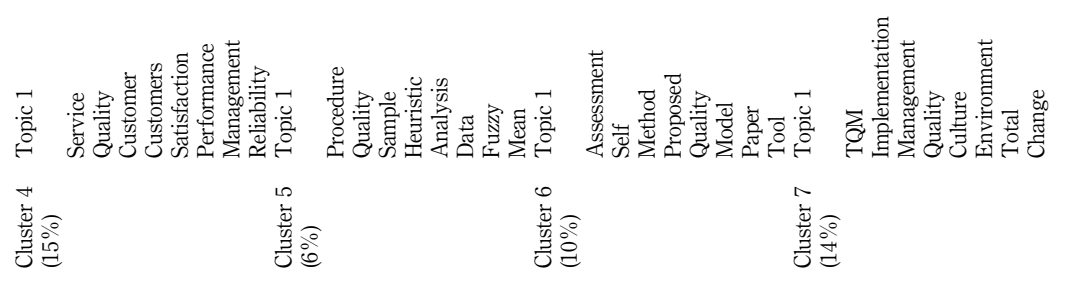





\section{IJQRM}

34,7

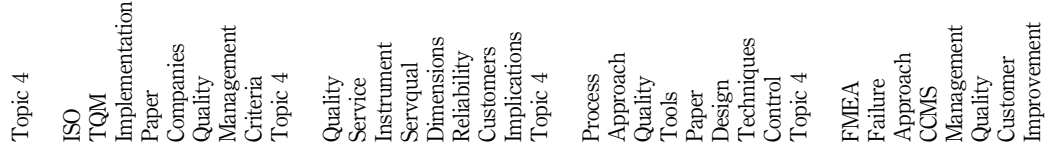

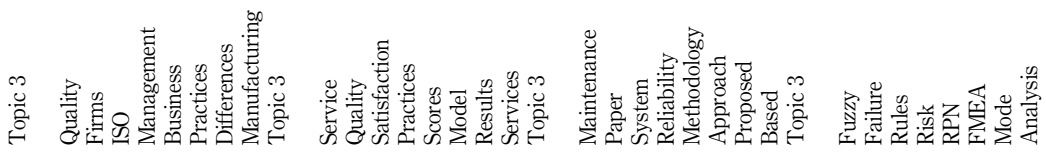

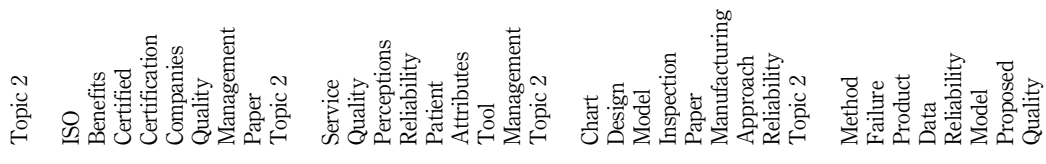

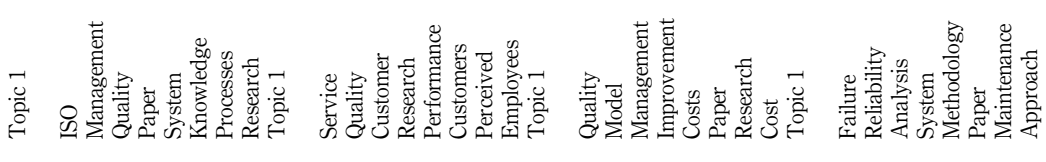

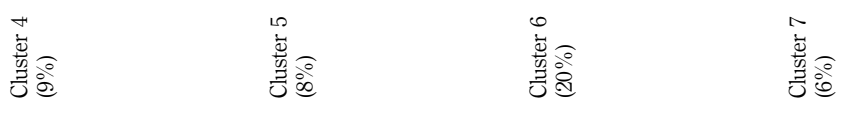

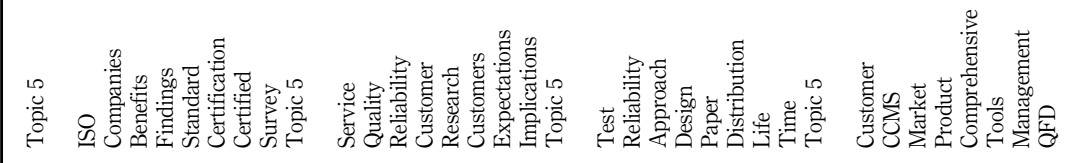

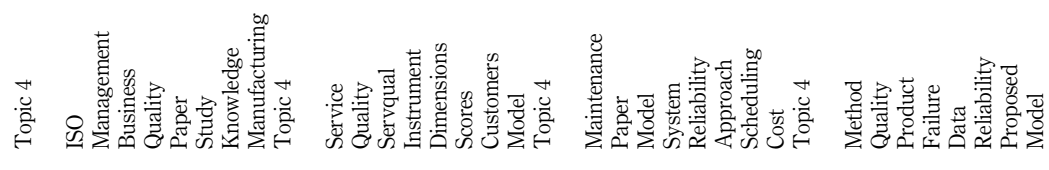

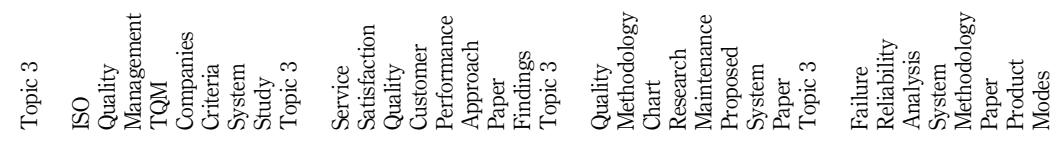

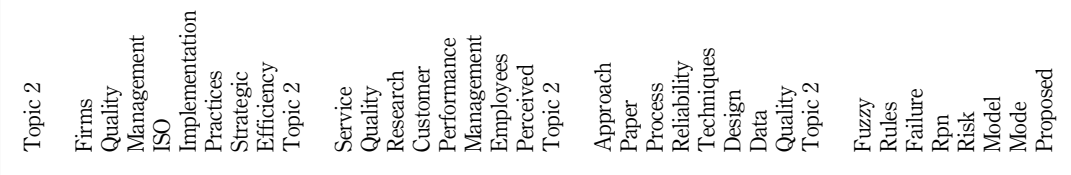

Table AII.

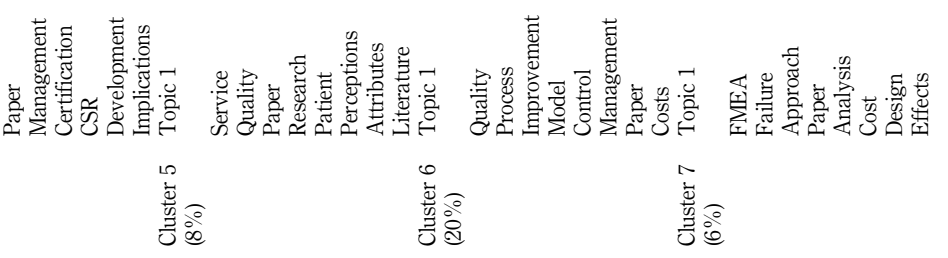



IJQRM

34,7

1010

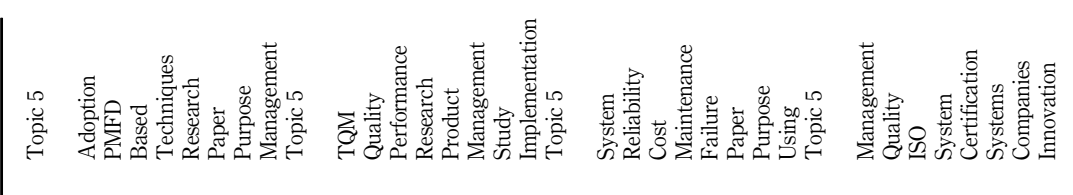

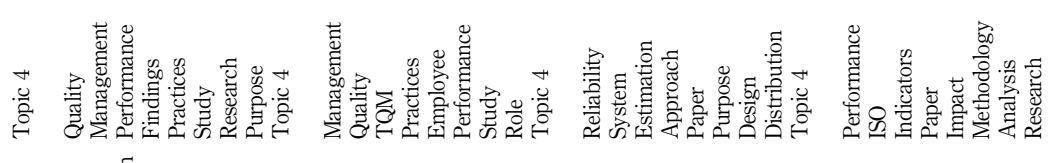

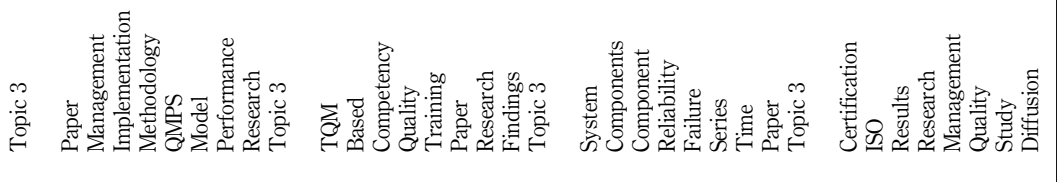

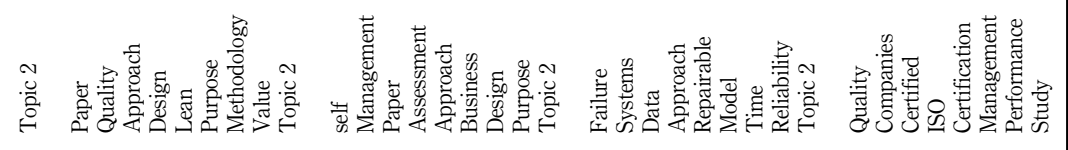

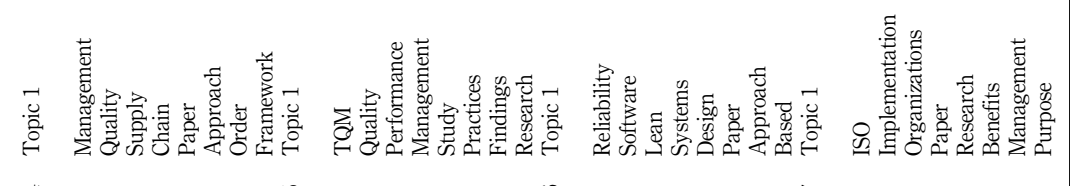

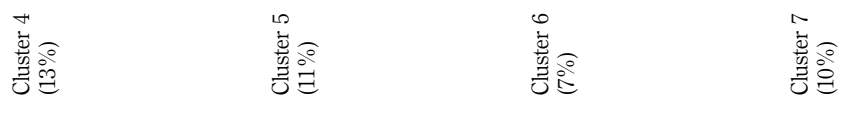

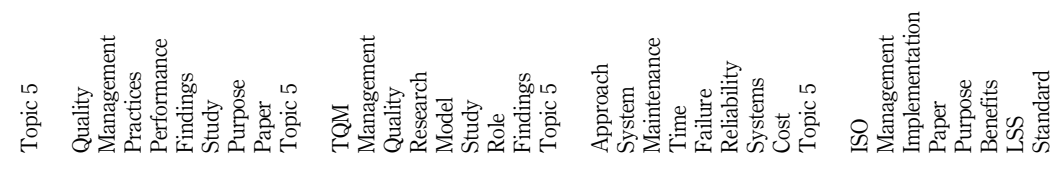

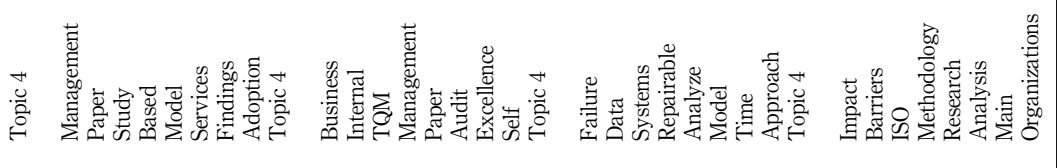

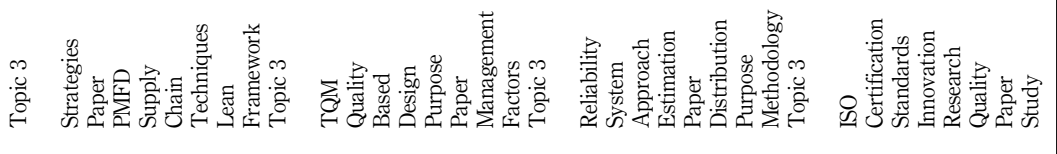

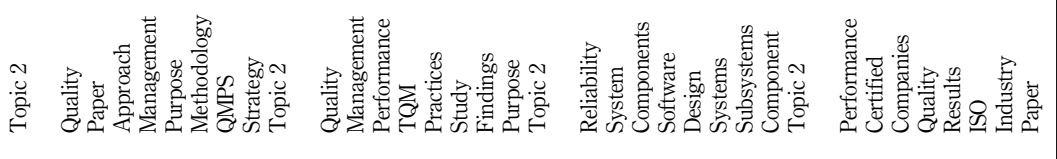

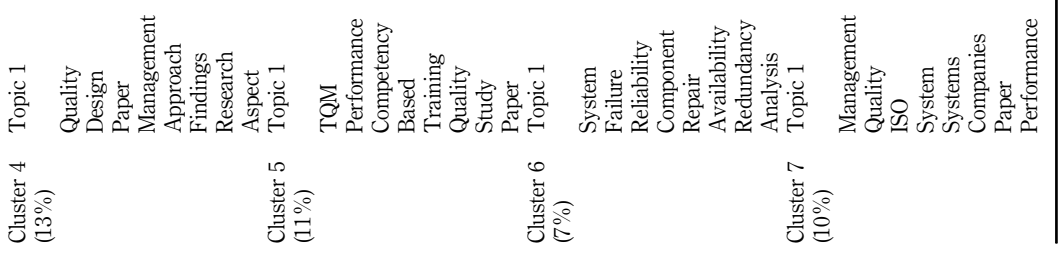


Appendix 3

Quality and reliability management

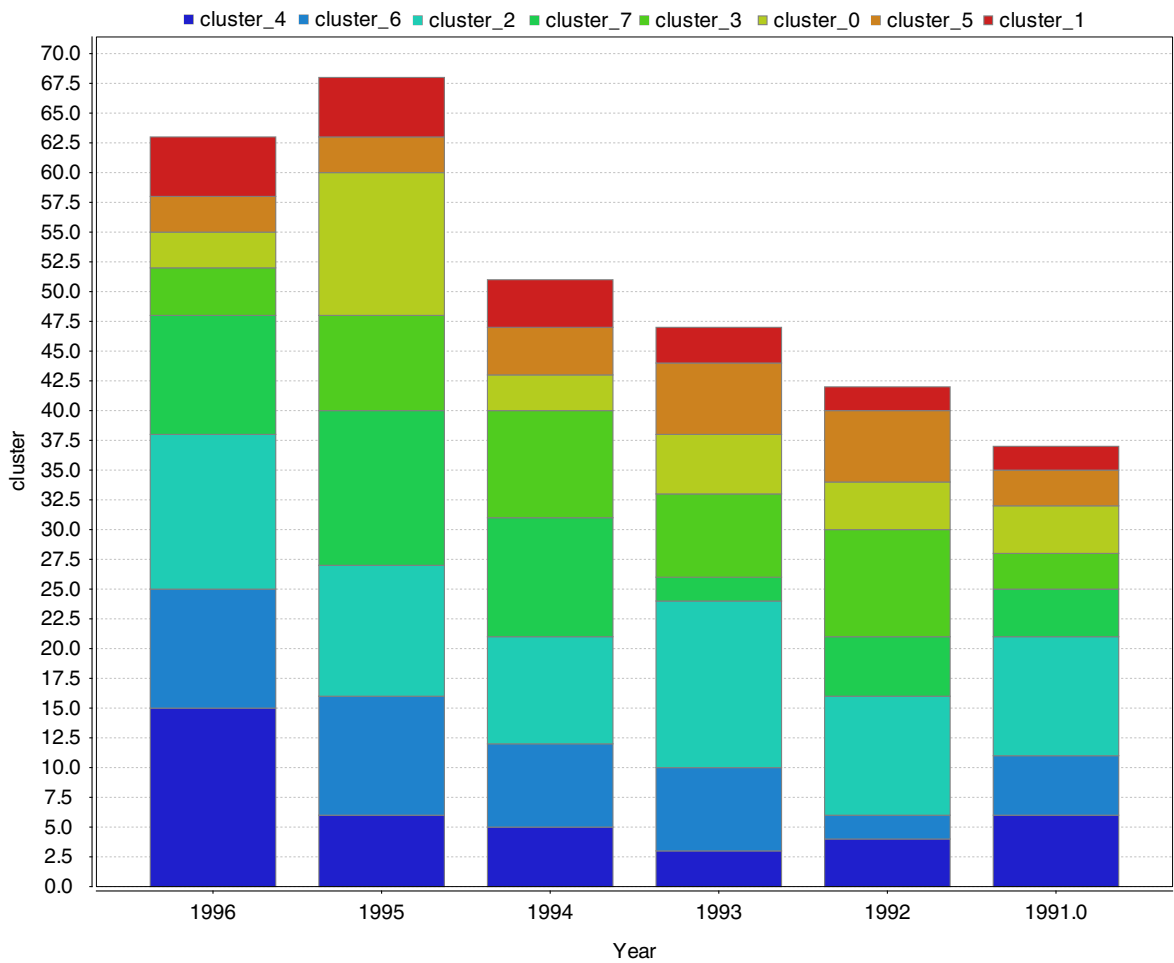

1011

Figure A1.

IJQRM 1991-1996

structured into 8 clusters 
IJQRM

34,7

\section{2}

Figure A2.

IJQRM 1997-2002

structured into

8 clusters

\section{Appendix 4}

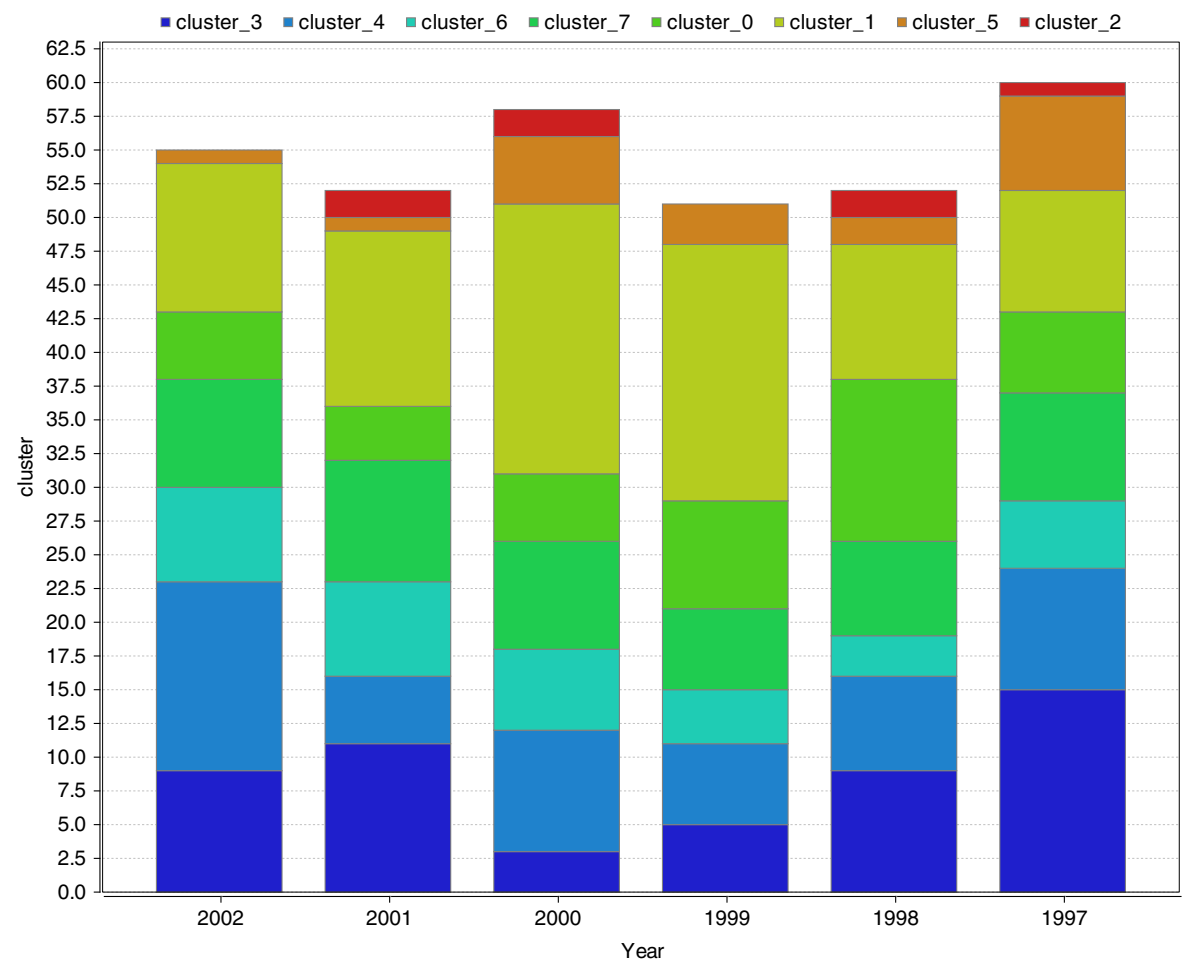


Appendix 5

Quality and reliability management

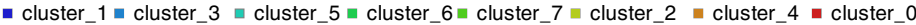

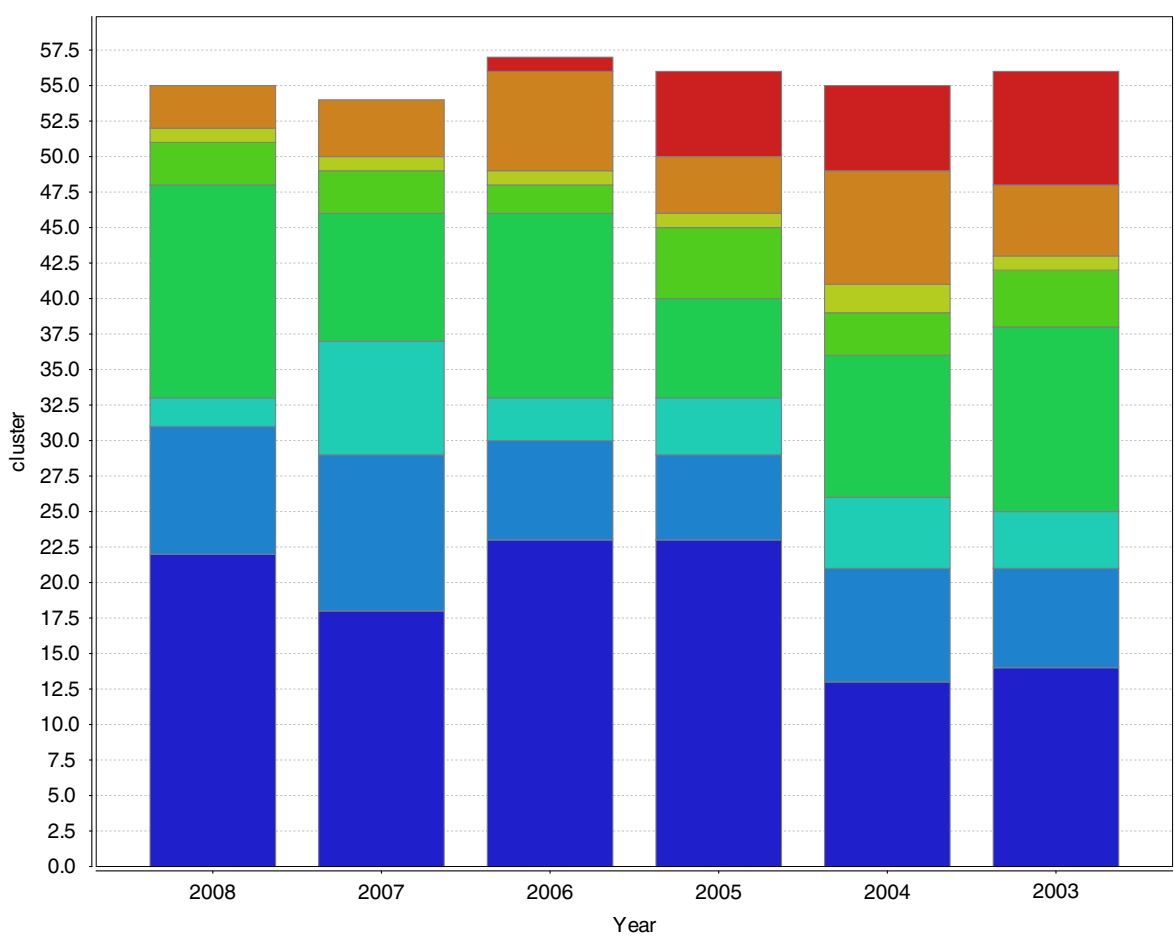

1013

Figure A3. IJQRM 2003-2008

structured into 8 clusters 
IJQRM

34,7

1014

Figure A4.

IJQRM 2009-2014

structured into 8

clusters

\section{Appendix 6}

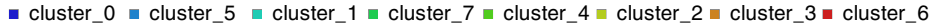

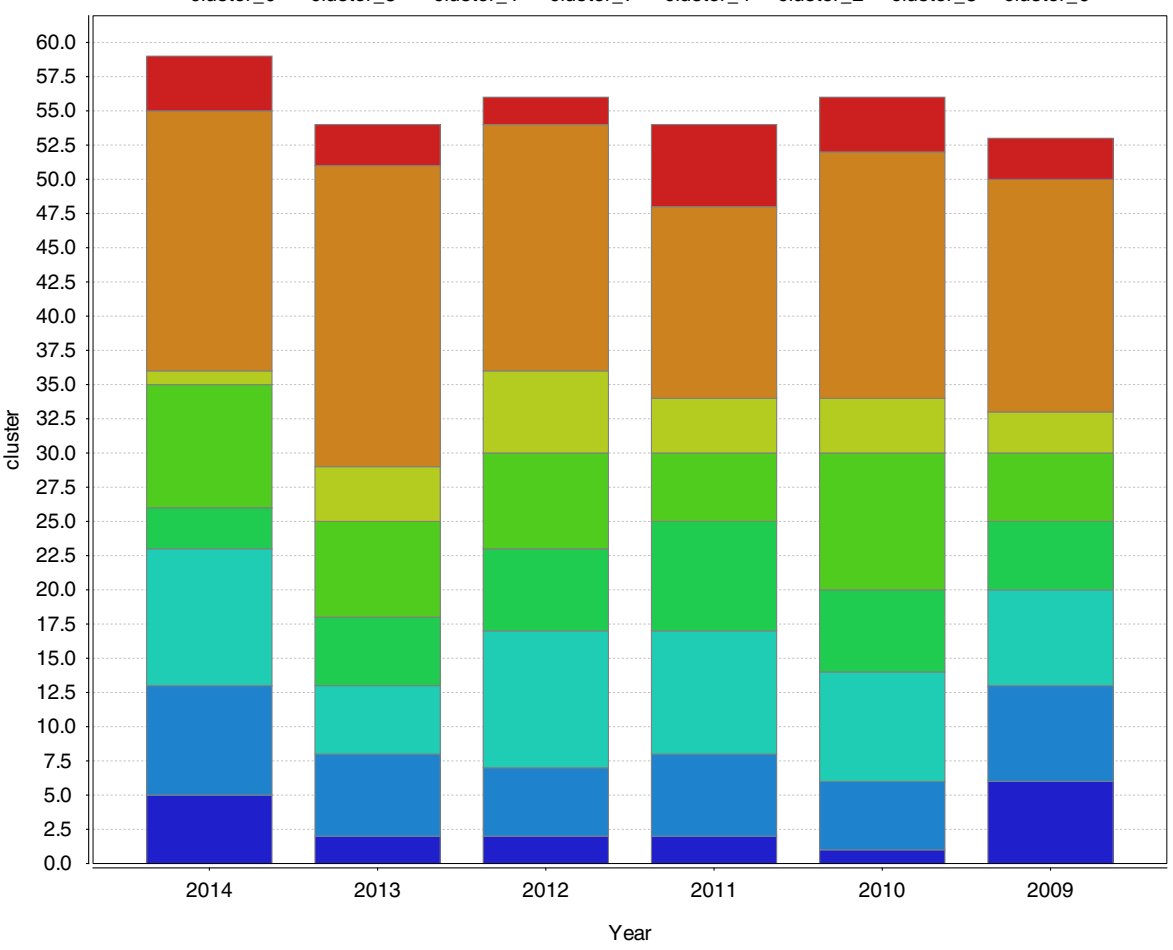

Corresponding author

Daniel Carnerud can be contacted at: daniel.carnerud@miun.se

For instructions on how to order reprints of this article, please visit our website: www.emeraldgrouppublishing.com/licensing/reprints.htm

Or contact us for further details: permissions@emeraldinsight.com 